\title{
PHOSPHATE STARVATION RESPONSE enables arbuscular mycorrhiza symbiosis
}

Debatosh Das ${ }^{1,2}$, Michael Paries ${ }^{3}$, Karen Hobecker ${ }^{3}$, Michael Gigl ${ }^{4}$, Corinna Dawid ${ }^{4}$, Hon-Ming Lam ${ }^{2,5}$, Jianhua Zhang $^{2,5,6 *}$, Moxian Chen ${ }^{1 *}$, Caroline Gutjahr ${ }^{3 *}$

\begin{abstract}
${ }^{1}$ State Key Laboratory Breeding Base of Green Pesticide and Agricultural Bioengineering, Key Laboratory of Green Pesticide and Agricultural Bioengineering, Ministry of Education, Research and Development Center for Fine Chemicals, Guizhou University, Guiyang, China. ${ }^{2}$ CUHK Shenzhen Research Institute, No. 10 Yuexing 2nd Road, Nanshan; Shenzhen, China. ${ }^{3}$ Plant Genetics, TUM School of Life Sciences, Technical University of Munich (TUM), Emil Ramann Str. 4, 85354 Freising, Germany. ${ }^{4}$ Chair of Food Chemistry and Molecular and Sensory Science, TUM School of Life Sciences, Technical University of Munich (TUM), Lise-Meitner-Str. 34, D-85354 Freising, Germany. ${ }^{5}$ State Key Laboratory of Agrobiotechnology, The Chinese University of Hong Kong, Shatin, Hong Kong. ${ }^{6}$ Department of Biology, Hong Kong Baptist University, Hong Kong.
\end{abstract}

ORCID IDs:

0000-0003-3729-5669 (DD); 0000-0002-7578-5813 (MP); 0000-0002-5052-289X (KH); 0000-0001-5342-2600 (CD); 0000-0002-5617-9236 (MG); 0000-0002-6673-8740 (HML); 0000-0003-4538-5533 (MC); 0000-0002-3819-2437 (JZ); 0000-0001-6163-745X (CG)

*Correspondence to:

Caroline Gutjahr; caroline.gutjahr@tum.de, +49-8161 712680

Jianhua Zhang; izhang@hkbu.edu.hk, +852-34112191

Moxian Chen; cmx2009920734@gmail.com, +86-13601466677

Arbuscular mycorrhiza (AM) is a widespread symbiosis between roots of the majority of land plants and Glomeromycotina fungi. AM is important for ecosystem health and functioning as the fungi critically support plant performance by providing essential mineral nutrients, particularly the poorly accessible phosphate, in exchange for organic carbon. AM fungi colonize the inside of roots and this is promoted at low but inhibited at high plant phosphate status, while the mechanistic basis for this phosphate-dependence remained obscure. Here we demonstrate that a major transcriptional regulator of phosphate starvation responses in rice PHOSPHATE STARVATION RESPONSE 2 (PHR2) regulates AM. Root colonization of phr2 mutants is drastically reduced, and PHR2 is required for root colonization, mycorrhizal phosphate uptake, and yield increase in field soil. PHR2 promotes AM by targeting genes required for pre-contact signaling, root colonization, and AM function. Thus, this important symbiosis is directly wired to the PHR2-controlled plant phosphate starvation response.

\section{Introduction}

Phosphate $\left(\mathrm{P}_{\mathrm{i}}\right)$ is vital for plant growth, yield, and survival, but in most soils, it is poorly available to plants. To facilitate $\mathrm{P}_{\mathrm{i}}$ acquisition, $80 \%$ of land plants associate with Glomeromycotina fungi in a 450-million-year-old arbuscular mycorrhiza (AM) symbiosis, in which the fungus provides mineral nutrients in exchange for carbon ${ }^{1}$. AM symbioses also improve plant stress resistance and soil stability, making AM a promising addition to sustainable agricultural practices ${ }^{2}$. Symbiotic plants acquire most of their phosphate through AM fungi (AMF) ${ }^{3}$. The fungi collect $P_{i}$ via a subterranean hyphal network and release it inside the root cortex via tree-shaped arbuscules ${ }^{1}$. It has been observed for decades that AM symbiosis is suppressed when the plant $P_{i}$ status is high, likely to conserve carbon ${ }^{4-6}$. However, the molecular mechanisms interconnecting plant $P_{i}$ status with AM symbiosis development and function have largely remained elusive. Under $P_{i}$ deficiency, plants activate a range of adaptive responses including transcriptomic, metabolic, and developmental changes ${ }^{7}$. A majority of these is controlled by PHOSPHATE STARVATION RESPONSE (PHR) proteins, first discovered in the AM-incompetent species Arabidopsis thaliana and the unicellular alga Chlamydomonas reinhardtii ${ }^{8}$. PHRs belong to the MYB transcription factor (TF) family and bind to P1BS motifs (GNATATNC) in the promoters of phosphate starvation- 
bioRxiv preprint doi: https://doi.org/10.1101/2021.11.05.467437; this version posted November 6, 2021. The copyright holder for this preprint (which was not certified by peer review) is the author/funder, who has granted bioRxiv a license to display the preprint in perpetuity. It is made available under aCC-BY-NC 4.0 International license.

induced (PSI) genes ${ }^{8,9}$. Interestingly, in Lotus japonicus, P1BS motifs have also been found in the promoters of several genes induced during arbuscule development in root cortex cells ${ }^{10,11}$, often in combination with CTTC/MYCS motifs, which are bound by an AM-induced WRINKLED (WRI,) TF $^{11,12}$. Therefore, we hypothesized that PHR may regulate $P_{i}$ responsive AM development ${ }^{13}$. In contrast to Arabidopsis, $L$. japonicus and the important staple crop rice form AM symbioses ${ }^{14}$. The rice genome contains four PHR genes (PHR1-4), but based on promoter:GUS activity, PHR2 is most broadly expressed in roots and especially in tissues relevant for $A M^{15,16}$. Thus, we focused on PHR2 in rice to investigate the role of this central phosphate starvation response regulator in AM.

We demonstrate that rice PHR2 is required for root colonization by AMF. Root colonization of phr2 mutants is drastically reduced at low $\mathrm{P}_{\mathrm{i}}$, while its overexpression partially rescues root colonization at high $\mathrm{P}_{\mathrm{i}}$. Even in non-colonized roots, the expression of almost $70 \%$ of genes that have been genetically shown to be relevant for AM development and function or that are induced during AM is reduced in phr2 mutants compared to wild type. PHR2 directly targets essential genes for major and indispensable symbiotic processes, i. e. pre-contact signal exchange between the symbionts, accommodation of the fungus inside the root, and symbiotic nutrient exchange. In addition, PHR2 is required for root colonization, mycorrhizal phosphate uptake, and AM-mediated yield-promotion in field soil and is sufficient to promote root colonization at high $\mathrm{P}_{\mathrm{i}}$. Moreover, the role of PHRs in promoting AM is conserved in the legume $L$. japonicus. Thus, PHRs support AM development and function as part of the plant phosphate starvation response syndrome under phosphate deficiency, while after phosphate repletion, AM likely cannot develop due to repression of PHR activity through so-called SPX proteins ${ }^{17}$. AM symbiosis is thus directly wired to the plant phosphate starvation response via the master regulator PHR.

\section{Results}

\section{PHR2 promotes root colonization by AMF}

We examined root colonization by the model AMF Rhizophagus irregularis of wild type and phr2 mutants at low phosphate conditions $(25 \mu \mathrm{M} \mathrm{P} ;$; LP). Wild type roots were well colonized, but root colonization was severely impaired in a phr2 insertion mutant ${ }^{17}$ and an independent CRISPRCas9 generated phr2 mutant ('phr2(C) ${ }^{18}$; Fig. 1A-D). We observed very few colonization attempts on mutant roots, mainly comprising hyphopodia or very few intraradical hyphae, resembling mutants in common symbiosis genes that encode proteins of a signaling cascade which is critically required for fungal root entry and $A M$ development ${ }^{14}$. Only in very rare colonization units, arbuscules with wild-type-like morphology developed in the phr2 mutants (Fig. 1E-H, Fig. S1).

As PHR2 is critical for root colonization at LP, we examined whether ectopic expression of PHR2 driven by the $35 \mathrm{~S}$ promoter (35S:PHR2) ${ }^{17}$ enables root colonization at higher $\mathrm{P}_{\mathrm{i}}$ conditions. At LP, total colonization, arbuscules, and vesicles were slightly increased in 35S:PHR2 as compared to wild type. However, at medium (200 $\left.\mu \mathrm{M} \mathrm{P}_{\mathrm{i}}, \mathrm{MP}\right)$ and high $\mathrm{P}_{\mathrm{i}}\left(500 \mu \mathrm{M} \mathrm{P}_{\mathrm{i}}, \mathrm{HP}\right)$ wild type and phr2 were hardly colonized, while 35 S:PHR2 enabled $40 \%$ and $20 \%$ total root length colonization and $25 \%$ and $5 \%$ colonization with arbuscules, respectively (Fig. 1A-D, Fig. S2, Fig. S3). Together this indicates that PHR2 promotes AM development at $P_{i}$ starvation and its inactivity may be responsible for the absence of $A M$ at high phosphate, as described for other phosphate starvation responses ${ }^{17,19}$. A role of PHR2 in supporting arbuscule development is supported by the activity pattern of its promoter. Shi et al., 2021 showed that the PHR2 promoter is active across all tissue layers in non-colonized rice roots. In colonized roots, a stronger promoter activity was observed in arbuscule-containing cells with an overall increased GUS activity in large lateral roots ${ }^{20}$.

\section{PHR2 activates AM-relevant genes}

To explain the role of PHR2 in AM, we performed RNA sequencing for non-inoculated (Mock) and $R$. irregularis-inoculated (AM) roots of phr2 at LP, 35S:PHR2 at HP, and wild type at both $\mathrm{P}_{\mathrm{i}}$ conditions (Fig. 2, Fig. S4 and Data S1). A larger number of genes differed in expression in phr2 
bioRxiv preprint doi: https://doi.org/10.1101/2021.11.05.467437; this version posted November 6, 2021. The copyright holder for this preprint (which was not certified by peer review) is the author/funder, who has granted bioRxiv a license to display the preprint in perpetuity. It is made available under aCC-BY-NC 4.0 International license.

or 35S:PHR2 vs. wild type in AM compared to Mock roots (Fig. 2A). The drastic transcriptome modulation upon AM indicated by principal component analysis in the wild type at LP was clearly reduced for phr2 (Fig. 2B). At HP, the transcriptomes of all 35S:PHR2 and wild-type samples clustered together, but they separated when analyzed separately from LP samples (Fig. S5), suggesting a weaker but still remarkable effect of ectopic PHR2 expression on the AM root transcriptome at HP. Interestingly, the expression of AM-relevant genes is already compromised in phr2 Mock roots (without root colonization), similar to wild type at HP (Fig. 2C-F, Data S2), including 16 genes with genetically determined and (for most of them) essential functions in AM (Fig. 2E). These include genes encoding receptors involved in the perception of fungal signals prior to root contact (CERK1, NFR5), common symbiosis genes involved in signal transduction and regulation of colonization (SYMRK, CCaMK, CYCLOPS, SLR1/DELLA, NSP1, NSP2, VAPYRIN), genes involved in strigolactone biosynthesis for activation of the fungus in the rhizosphere prior to contact $(C C D 7, C C D 8 B)$, genes involved in the regulation of colonization (KIN2), genes involved in karrikin signaling and apocarotenoid biosynthesis (DLK2C, ZAS), and genes encoding periarbuscular membrane-localized ABCG and phosphate transporters for nutrient exchange (STR1, PT11, PT13) ${ }^{21,22}$. In addition, the expression of one-fifth of AM-induced genes in wild type is reduced already in the absence of AMF in phr2 (Fig. 2F and Data S3). Together, this suggests that PHR2 conditions the root for AM symbiosis at low phosphate and that the lower cumulative expression of AM-relevant genes impairs AM in phr2 mutants.

We compiled a list of 205 genes, called 'AM genelist' (Data S4), containing genes with a genetically determined or putative function in AM, based on phylogenomic and/or conserved expression patterns across AM-competent plant species ${ }^{23}$. Almost $70 \%$ of genes in the AM genelist were less expressed in phr2 vs. wild type, demonstrating that PHR2 is an important regulator of AM (Fig. 2G). Consistent with the low colonization of phr2 and the presence of PHR binding sites in the promoters of some of the orthologs in Lotus japonicus ${ }^{11}$, the activation of AMinduced genes was impaired, including a number of genes encoding (receptor) kinases, transcription factors, transporters, and enzymes with genetically determined function in AM (Fig. S6-S9, Data S5-S7). Furthermore, many of these genes showed reduced expression in phr2 even in the absence of the fungus (Fig. S7). qPCR recapitulated this expression pattern of a selected subset of important AM-relevant genes (Fig. S9). Some of these were activated by 35S:PHR2 at $\mathrm{HP}$ and most of them at MP, consistent with the degrees of promotion of AM by 35S:PHR2 at these non-permissive conditions (Fig. 1A-D, Fig. S2-S3, S9-S10). Furthermore, 213 DEGs that are less expressed in phr2 roots show increased expression in non-colonized smax1 or d3 smax1 roots, which show the opposite AM phenotype to phr2, i. e. they are colonized more extensively than wild type ${ }^{24}$, and 41 of these genes are additionally shared with the AM genelist (Figure $2 G$, Data S7). SMAX1 is a negative regulator of karrikin signaling and needs to be removed through proteasomal degradation after binding to a complex of the karrikin receptor KAI2 and the SCFMAX2 complex to enable $A M$ in rice ${ }^{24,25}$. Thus, karrikin signaling and PHR2 seem to target partially overlapping genes for regulating AM.

\section{PHR2 directly targets AM-relevant genes}

To understand whether PHR2 directly targets AM-relevant genes, we performed chromatin immunoprecipitation followed by DNA sequencing (ChIP-Seq). Since we surprisingly found that PHR2 promotes the expression of AM-relevant genes already in the absence of AMF at LP, we chose to perform ChIP-Seq under this condition. For the two independent replicates, more than $60 \%$ of PHR2 binding sites were found upstream of ATG (Fig. S11). Motif enrichment analysis of DNA sequences associated with PHR2 binding sites revealed the P1BS element (GNATATNC) among the top 2 enriched motifs in both ChIP replicates (Data S8, Fig. S12). Peaks representing PHR2 binding sites were annotated to nearby genes and 435 genes were shared between the two replicates (referred to as "PHR2 targets"; Fig. S13A, Data S8). 77\% of these PHR2 targets with reduced expression in phr2 contained P1BS/P1BS-like motifs in the sequence between the 
bioRxiv preprint doi: https://doi.org/10.1101/2021.11.05.467437; this version posted November 6, 2021. The copyright holder for this preprint (which was not certified by peer review) is the author/funder, who has granted bioRxiv a license to display the preprint in perpetuity. It is made available under aCC-BY-NC 4.0 International license.

transcriptional start site (TSS) and 3000 bp upstream of the TSS (Fig. S13B, Data S9). ChIP-Seq quality was further validated by strong PHR2-binding peaks at P1BS elements in the promoter regions of the previously known PHR2-targets, GDPD2, IPS1, and SPX1/2/3 ${ }^{17,26,27}$ (Fig. S14 and Data S10). An overlap of PHR2 targets with DEGs reduced in phr2 vs wild type resulted in 162 overlapping genes, for which GO enrichment analysis revealed that most of these were involved in "Cellular response to phosphate starvation" and motif enrichment in the $3 \mathrm{~kb}$ region upstream of TSS revealed P1BS motif (GNATATNC) as the topmost hit (Fig. 3A-B, Fig. S13C-D). 17 genes overlapped among the two ChIP replicates and the AM genelist, and these represent a significant enrichment of AM-relevant genes in high-confidence PHR2 targets, when compared to the whole rice genome ( $p$-value of $6.4 \times 10^{-11}$ ) (Fig. S15). An overlap also showed 27 common genes (including genes from individual ChIP replicates), 15 of which were repressed in phr2 vs wild type and common to both ChIP replicates (Fig. 3A, Fig. 3C, and Data S10). These 15 genes contain 8 with established and crucial roles in AM. Except for PT11, which is required for mycorrhizal phosphate uptake and arbuscule maintenance, all these genes are indispensable for pre-contact signaling and necessary for or involved in important early events of fungal root entry (Fig. 3C), congruous with the phr2 AM phenotype. The remaining 12 genes that were hit in only one ChIPSeq replicate included the genes CYCLOPS, SLR1/DELLA, required for root colonization and arbuscule formation $^{22}$ (Fig. 3C) as well as GRAS16 and SMAX1, which are positive and negative regulators of $A M$ respectively ${ }^{28,24}$.

Specific binding of PHR2 to the P1BS/P1BS-like motif in the promoters of the 8 AM-relevant PHR2 targets detected in both ChIP-Seq replicates was confirmed by ChIP-qPCR except for CERK1 (Figs. S16-S17). Surprisingly, for the CERK1 promoter, we found moderate enrichment at a CTTC/MYCS motif nearby the P1BS motif. It is possible that a CTTC-binding protein (e. g. a WRI transcription factor ${ }^{12}$ ) forms a complex with PHR2 to regulate CERK1 transcription and that this CTTC/MYCS binding factor has a stronger affinity to the DNA than PHR2, leading to enrichment of this motif after PHR2 pulldown. Using transactivation assays in Nicotiana benthamiana leaves, we found that the promoter of the established PHR2 target GDPD2 and three novel and AM-

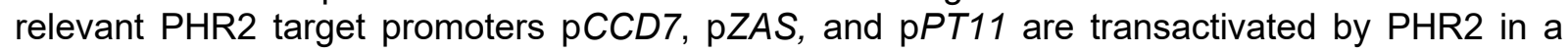
P1BS-dependent manner (Fig. 3D-E), confirming the ChIP-Seq results.

The binding of and transactivation of the promoter of the strigolactone (SL)-biosynthesis gene CCD7 by PHR2 (Fig. 3C-E) and the decreased expression of CCD8B in the phr2 mutant (Fig. 2E, Fig. S9-10) are consistent with the observation that strigolactone biosynthesis is increased at $\mathrm{P}_{\mathrm{i}}$ starvation ${ }^{29}$. Exuded SL in the rhizosphere activates AMF and is crucial for relevant levels of root colonization, while root colonization of $c c d 7$ and ccd8 mutants with defects in SL biosynthesis is strongly reduced ${ }^{30-33}$. To understand the impact of mutating phr2 on SL exudation we quantified the canonical rice SL 4-deoxyorobanchol as well as 2 isomers of Methoxy-5-deoxystrigol in the root exudates of wild type, phr2, and 35S:PHR2 (Fig. 3F). The amount of all three compounds was reduced by at least half in phr2 root exudates as compared to the wild type, while the Methoxy-5-deoxystrigol isomers were slightly increased in the exudates of 35S:PHR2. This indicates that PHR2 indeed regulates SL biosynthesis and thereby the amount of SL in the root exudate. We examined whether exogenous supplementation of phr2 with SL can restore AM colonization. Treatment of roots with $100 \mathrm{nM}$ of the synthetic SL analogue, rac-GR24 led to a significant increase in total colonization and vesicles in phr2 roots but not in wild type roots, which probably exude saturating amounts of SL (Fig. 3G). Thus, part of the inability of phr2 to support AM is due to reduced SL exudation, while another part can be explained by reduced expression of other genes required for root colonization and AM functioning (Fig. 2E).

\section{Transcript accumulation of gibberellin-related genes is altered in phr2}

Gibberellin (GA) treatment inhibits AM development because AM formation requires DELLA, the proteolytic target of GA-signalling ${ }^{34,35}$. It was recently shown that GA is also involved in the suppression of AM in response to HP, as GA-deficient Nicotiana tabacum plants were less 
bioRxiv preprint doi: https://doi.org/10.1101/2021.11.05.467437; this version posted November 6, 2021. The copyright holder for this preprint (which was not certified by peer review) is the author/funder, who has granted bioRxiv a license to display the preprint in perpetuity. It is made available under aCC-BY-NC 4.0 International license.

sensitive to AM inhibition by HP than wild type ${ }^{36}$. To understand whether GA signaling participates in the regulation of $A M$ in response to phosphate downstream of PHR2, we mined the RNAseq and ChIP-Seq data for GA-biosynthesis and signaling genes. In addition to DELLA and the GIBBERELLIN INSENSITIVE DWARF 2 (GID2), encoding an F-box protein required for GAperception being direct targets of PHR2 (Fig. 3C, Fig. S.18D), we found that GA-related genes were enriched in genes deregulated in phr2 (Fig. S18A). GA biosynthesis genes had lower expression levels in Mock roots of phr2 mutants as compared to wild type, while the transcript levels of three genes encoding enzymes involved in de-activating GA (GA13ox2, GA2ox3, GA20x7) are increased in phr2 (Fig. S18B). Thus, the expression of several genes involved in GA metabolism is controlled by PHR2.

The role of PHR in regulating AM is conserved in the dicotyledon Lotus japonicus

We used the model legume Lotus japonicus to understand whether the role of PHR in AM is conserved in dicotyledons. The $L$. japonicus genome contains three $P H R$ genes, which we named PHR1A, PHR1B, and PHR1C (Fig. S19A). A LORE1 retrotransposon insertion line ${ }^{37}$ was obtained for PHR1A (Fig. S19B-C). Mutation of Ljphr1a was sufficient to cause a significant reduction in colonization by $R$. irregularis as compared to the wild type of hairy roots transformed with an empty vector and grown at LP. This indicates that the role of PHR in AM is conserved in $L$. japonicus. However, there may be redundancy among the three PHR proteins, and the AM phenotype may be stronger in double and triple phr mutants. Transgenic expression of PHR1A driven by a Ubiquitin promoter in phr1a hairy roots restored colonization to wild-type levels. Furthermore, Ubiquitin promoter-driven expression of PHR1A significantly increased root colonization at high phosphate as compared to the wild type (Fig. 4A). We examined, whether mutation of PHR1A leads to reduced expression of AM-relevant genes in L. japonicus, and monitored transcripts of selected candidate genes in Mock roots by RT-qPCR, namely the common symbiosis genes SYMRK, CCaMK, and CYCLOPS and the three SL biosynthesis genes D27, CCD7, and CCD8. Similar to rice phr2 mutants, the expression of SYMRK, CCaMK and CYCLOPS was reduced in roots of phr1a. However, no significant reduction in transcript accumulation of the SL biosynthesis genes was observed, even though one P1BS is located in the promoter of each of these genes (Fig. S20). It is possible that one of the other PHRs regulates their expression. Alternatively, SL biosynthesis genes may not be regulated by PHRs in Lotus japonicus.

\section{PHR2 promotes AM and yield in field soil}

To assess the importance of rice PHR2 in supporting AM in field soil and in promoting plant performance via AM we conducted a greenhouse experiment with soil from a rice paddy field with (HP) or without (LP) P fertilization (Fig. 5 and Figs. S21-S25). At LP, inoculation with $R$. irregularis caused a significant increase in several important agronomic parameters: total shoot phosphorus $(P)$ and shoot $P$ concentration, root fresh weight, and most importantly seed setting and 1000 grain weight in wild type and 35S:PHR2. However, these parameters remained unchanged or decreased in phr2 at LP (Fig. 5; Fig. S22), showing that phr2 is required for AM-mediated yield increase in field soil. At HP, total shoot phosphorus $(P)$, root fresh weight, seed setting, and 1000 grain weight remained the same in wild type independent of AMF presence. However, in 35S:PHR2 these parameters increased in response to AM. Furthermore, 35S:PHR2 caused a significant response to AM for plant height, panicle length, and shoot dry weight at LP, HP, or both (Fig. S22A-C). Consistently, 35S:PHR2 enabled AM colonization in field soil even at HP, accompanied by increased expression of the AM marker genes $A M 1, A M 3, A M 14 / A R K 1$, and $P T 11^{14}$ (Figs. S23, S24, S25B).

Our data confirm previous observations that $35 \mathrm{~S}$ :PHR2 reduces plant growth as compared to wild type (Fig. 5, Fig. S22). This may be due to $\mathrm{P}_{\mathrm{i}}$ toxicity ${ }^{15}$; changes in hormone biosynthesis and/or signaling or other pathways affecting development. Interestingly, AM mitigates this negative effect 
bioRxiv preprint doi: https://doi.org/10.1101/2021.11.05.467437; this version posted November 6, 2021. The copyright holder for this preprint (which was not certified by peer review) is the author/funder, who has granted bioRxiv a license to display the preprint in perpetuity. It is made available under aCC-BY-NC 4.0 International license.

on rice performance, perhaps because it promotes the uptake of other nutrients, which consequently become less limiting and/or affects other pathways regulating plant growth.

\section{Discussion}

Here we demonstrate that rice PHR2 is essential for the establishment of AM symbiosis under laboratory conditions as well as for AM-mediated improvement of rice yield in LP paddy field soil. PHR2 supports AM development at LP because it promotes the expression of a number of genes required for AM development and function already in the absence of AMF. This possibly occurs through the effect of PHR2 on chromatin accessibility, as recently shown in Arabidopsis ${ }^{38}$. We detected direct PHR2 targets using ChIP-Seq in the absence of AMF and these comprise strigolactone biosynthesis genes needed for strigolactone exudation to activate the fungus ${ }^{31,33}$, membrane receptors needed for perception of fungal signals ${ }^{39,40}$ and genes belonging to the common symbiosis signal transduction cascade, which is thought to relay the signals to the nucleus to activate gene expression, and which is required for fungal entry into the root ${ }^{14}$. Furthermore, PHR2 activates targets genes encoding transporters needed for nutrient exchange at the peri-arbuscular membrane, such as $P T 11^{41}$. Thus, PHR2 appears to be required for the activation of genes involved in several steps of arbuscular mycorrhiza development from initiation of root colonization to its functioning in nutrient exchange (Fig. 6).

Shi et al. 2021 performed a large yeast-1-hybrid screen using 47 promoters of genes activated by AM predominantly in arbuscule-containing cells. They found that a large proportion of them was bound by PHR2, consistent with the previous observation that a number of their orthologs in $L$. japonicus carry the P1BS element in their promoter ${ }^{11}$. Interestingly, although transcripts of these genes were reduced in phr2 mutants in our study, which can be a symptom of reduced root colonization, we did not capture most of these genes in our ChIP-Seq experiment except for the AM-specific transporter genes PT11 and AMT3.1. We conducted ChIP-Seq from non-colonized roots and it is possible that additional AM-induced transcription factors are necessary to stabilize PHR2-binding to the promoters of these AM-induced genes. However, our ChIP-Seq approach enabled us to identify unexpected PHR2 targets involved in pre-contact symbiotic signaling and early stages of symbiosis, which were not present in the pre-selected set of promoters analyzed by $\mathrm{Y} 1 \mathrm{H}^{20}$.

At HP the movement of PHR2 to the nucleus and its binding to promoters is inhibited by SPX proteins, which act as phosphate sensors ${ }^{17,20,42,43}$. Consistently, it appears that AM development is attenuated at HP due to SPX-mediated inhibition of PHR2-mediated transcriptional activation of AM-relevant genes and likely not due to active suppression ${ }^{13}$ as previously suggested. This is consistent with the finding that ectopic expression of PHR2, driven by a strong constitutive promoter allows AM development at HP, likely because PHR2 outnumbers SPX proteins when it is overexpressed. Importantly, a recent study ${ }^{20}$ showed that quadruple mutants in rice SPX genes resulted in significantly increased root colonization independent of the phosphate concentration in the fertilizer, while ectopic SPX expression led to significantly reduced root colonization. In contrast, Medicago truncatula SPX1 and SPX3 were shown to positively affect root length colonization by promoting the expression of SL biosynthesis genes. However, they also seemed to promote arbuscule degeneration and turnover, indicating a dual role of these proteins in regulating $A M$ in $M$. truncatula ${ }^{44}$. The contrasting findings in rice and $M$. truncatula raise the possibility that different SPX family members play divergent roles in AM or that they differently affect $A M$ in grasses vs legumes.

We show that the role of PHRs in AM is conserved in the model legume $L$. japonicus. It is therefore likely, that AM symbiosis is a part of the PHR-mediated phosphate starvation response syndrome at least across the angiosperms. It will be interesting to learn whether this hypothesis can be confirmed in other clades of the vascular and early-diverging non-vascular plants. In summary, we provide important insights into the regulation of AM by the plant phosphate status, which has a broad significance in agriculture and terrestrial ecosystems. 
bioRxiv preprint doi: https://doi.org/10.1101/2021.11.05.467437; this version posted November 6, 2021. The copyright holder for this preprint (which was not certified by peer review) is the author/funder, who has granted bioRxiv a license to display the preprint in perpetuity. It is made available under aCC-BY-NC 4.0 International license.

\section{Methods \\ Plant material, growth conditions, and plant co-cultivation with AM fungi}

Oryza sativa L. ssp. japonica genotypes used in this work were wild type (cv. ZH11) and CRISPRCas9 generated phr2(C) ${ }^{18}$ and wild type (cv. Nipponbare), phr2, 35S:PHR2, and 35S:PHR2$F L A G^{17}$. Rice seeds were sterilized by incubating in absolute ethanol for $2 \mathrm{~min}$, then in sterilization solution ( $10 \%$ Clorox $+0.1 \%$ SDS) for 30 min and subsequently in autoclaved distilled water for $1 \mathrm{hr}$. Seeds were germinated on agar plates and kept in the dark for 3 days at $27^{\circ} \mathrm{C}$ and $60 \%$ air humidity in a controlled plant growth chamber. Subsequently, germinated seedlings were exposed to light and grown for 2 weeks in a long-day photoperiod (16h light/8h dark) in the same temperature and humidity conditions. 2-week-old seedlings were then transplanted to pots filled with quartz-sand and inoculated with 500 spores of Rhizophagus irregularis DAOM 197198 (Agronutrition, Toulouse, France) per plant and grown at the same conditions. Plants were fertilized with $50 \mathrm{ml}$ sterilized half-Hoagland media at $25 \mu \mathrm{M} \mathrm{P}_{\mathrm{i}}$ (low phosphate, LP), $200 \mu \mathrm{M} \mathrm{Pi}$ (medium phosphate, MP), and $500 \mu \mathrm{M} \mathrm{Pi}$ (high phosphate, HP) concentrations once a week and watered a second time per week with autoclaved distilled water.

For L. japonicus, ecotype Gifu wild type and phr1a mutants were used. The phr1a mutant corresponds to the LORE1 insertion line $30063054^{45}$. Seeds were scarified with sandpaper and surface sterilized with $0.1 \%$ SDS in $2 \% \mathrm{NaClO}$, washed 6 times with sterile water, and left to swell in sterile water with permanent inversion for 2 hours. The seeds were germinated on $0.8 \%$ B5Agar at $22{ }^{\circ} \mathrm{C}$ in darkness for 4 days and then in light for 3 days. Plates were then transferred to closed, sterilized cultivation pots (Duchefa, Os 140 Box, Green Filter), containing $450 \mathrm{~g}$ of sand and watered with modified B\&D medium, containing $250 \mu \mathrm{M} \mathrm{P} \mathrm{P}_{\mathrm{i}}$ (low phosphate) or $2.5 \mathrm{mM} \mathrm{P}_{\mathrm{i}}$ (high phosphate $)^{46}$. For arbuscular mycorrhiza colonization assays, plant roots were inoculated with 500 spores per plant of $R$. irregularis DAOM197198 (Agronutrition, Toulouse, France). The plants were grown for 4 weeks in a chamber set at $22{ }^{\circ} \mathrm{C}$ in a long-day photoperiod (16h light/8h dark) with $60 \%$ relative humidity.

\section{Quantification of root colonization and AM imaging}

Rice roots were harvested at 7 weeks post-inoculation (wpi) into $10 \% \mathrm{KOH}$ and boiled for 15 minutes followed by incubation in $10 \%$ acetic acid, ink staining, and $5 \%$ acetic acid de-staining as described ${ }^{46}$. Root pieces of $1 \mathrm{~cm}$ each were then mounted on a slide for observation under an inverted light microscope to quantify total $\mathrm{AM}$ colonization and \% of $\mathrm{AM}$ structures using the gridline intersect method ${ }^{47}$. Furthermore, images of these stained roots were taken using an OPTO EDU Binocular Compound Microscope (Opto-Edu, Beijing, China) fitted with 5MP USB 2.0 Color CMOS Digital Eyepiece Microscope Camera (AmScope, USA). For visualization of AM structures inside root cells, roots were stained with Wheat Germ Agglutinin, Alexa Fluor ${ }^{\mathrm{TM}} 488$ Conjugate $^{46}$. Roots were then visualized with a Zeiss LSM 710 Confocal Microscope (Zeiss, Germany) at 20X for a root overview or at 100X (oil) for details of arbuscules.

$L$. japonicus roots were stained with acid ink ${ }^{48}$. Root length colonization was quantified using a modified gridline intersect method (McGonigle et al., 1990) at 10X magnification under a light microscope Leica, type 020-518500 DM/LS (Leica, Germany).

\section{RNA extraction and RT-qPCR}

Plant roots were harvested, frozen in liquid nitrogen, and stored at $-80^{\circ} \mathrm{C}$. Frozen roots were ground into powder using mortar and pestle and the powder was immediately transferred to lysis extraction buffer and processed for RNA isolation using FastPure Plant Total RNA Isolation Kit (Polysaccharides \& Polyphenolics-rich) (Vazyme, China). Isolated RNA was checked for the absence of genomic DNA contamination by PCR. RNA was quantified with a Nanodrop (Thermo Scientific, USA). First-strand cDNA synthesis was carried out with HiScript $₫$ III RT SuperMix for qPCR (+gDNA wiper) (Vazyme, China). qPCR was conducted with primers indicated in Table S1 
and ChamQ Universal SYBR $®$ qPCR Master Mix (Vazyme, China) on a Bio-Rad CFX384 qPCR cycler (Bio-Rad Laboratories, Shanghai, China).

RNA from Lotus japonicus roots was extracted using the Spectrum Plant Total RNA Kit (Sigma, USA). DNA contamination was removed by Invitrogen DNAse I amp. grade (www.invitrogen.com) and RNA was tested for genomic DNA contamination by PCR. cDNA synthesis was performed with 600 ng RNA using the iScript cDNA synthesis kit (Bio-Rad, Germany). Real-time RT-PCR was performed with the qPCR GreenMaster high ROX mix (Jena Bioscience, Germany) and primers shown in Table S1. The qPCR reaction was run on an iCycler (Bio-Rad, Germany) according to the manufacturer's instructions. Thermal cycler conditions were: $95^{\circ} \mathrm{C} 2 \mathrm{~min}, 45$ cycles of $95^{\circ} \mathrm{C} 30 \mathrm{sec}, 60^{\circ} \mathrm{C} 30 \mathrm{sec}$ and $72^{\circ} \mathrm{C} 20 \mathrm{sec}$ followed by dissociation curve analysis. Expression levels were calculated according to the $\Delta \Delta \mathrm{Ct}$ method ${ }^{49}$. For each genotype and treatment, three biological replicates were monitored and each sample was represented by two to three technical replicates.

\section{RNASeq and Data analysis}

RNA was extracted as described above, checked for quality using an Agilent Bioanalyzer (Agilent, USA), and quantified in a Qubit 3.0 fluorometer (Invitrogen, USA). Samples with a RIN value of > 7 were used for library preparation (Illumina TruSeq Stranded Total RNA kit, Illumina, USA) and sequenced on an Illumina HiSeq 4000 to obtain 150bp paired-end reads. Raw fastq files were processed through adaptor-trimming. Clean reads were tested with FastQC (https://www.bioinformatics.babraham.ac.uk/projects/fastqc/) for base quality. Data were processed with a quasi-transcript mapping approach in Salmon ${ }^{50}$. Salmon was operated in the Conda environment inside Linux (https://anaconda.org/bioconda/salmon). Reads were mapped onto the Oryza sativa genome downloaded from Phytozome (https://phytozome.jgi.doe.gov/pz/portal.html). Read counts were obtained for rice transcripts at the gene level. Read counts were further processed through tximport in R/Bioconductor (https://cran.r-project.org/; R Core Team, 2013) for input into EdgeR for Data exploratory and differential expression analysis. Differentially expressed genes (DEGs) were obtained with the cut-off: absolute( $\log _{2}$ Fold-Change) $\geq 0.5845$ and FDR $\leq 0.05$. Heatmaps were prepared using the heatmap. 2 package in R/Bioconductor. AgriGO was utilized to find enriched GO terms for DEGs ${ }^{51}$. A list of genes implicated in AM was compiled based on previous studies in rice and other AM host plants and is referred to as "AM genelist" (Data S4). For genes identified to have a role in AM development of symbiosis in other AM host plants, reciprocal blast was used to identify the best match in rice.

\section{Chromatin immunoprecipitation (ChIP) and sequencing}

Chromatin immunoprecipitation was performed as described ${ }^{52}$ with few modifications as follows: 3-4-week-old 35S-PHR2-FLAG transgenic rice roots were ground to a fine powder in liquid nitrogen and stored at $-80^{\circ} \mathrm{C}$ until further use. Subsequently, $3 \mathrm{~g}$ of tissue powder were resuspended in cold extraction buffer with $1.5 \%$ formaldehyde and incubated at room temperature for 10 min with shaking, followed by quenching for 5 min with $125 \mathrm{mM}$ glycine and $750 \mathrm{mM}$ Tris's buffer. After Miracloth filtration and subsequent nuclei enrichment and lysis steps, the resulting chromatin was sheared in Bioruptor ${ }^{\circledR}$ Pico sonication device (Diagenode, USA) with settings of $30 \mathrm{sec}$ ON/30 sec OFF for 40 cycles. Agarose gel check on sonicated chromatin (reverse cross-linked and DNA purified) suggested that most fragments ranged from $150 \mathrm{bp}$ to 500 bp. Sonicated chromatin was concentrated using Microcon ${ }^{\circledR}$ Centrifugal Filters (Merck Millipore, USA). After centrifugation, sonicated chromatin supernatant was selected for immunoprecipitation. $20 \mu \mathrm{l}$ chromatin was saved at $-20^{\circ} \mathrm{C}$ for input DNA, and $100 \mathrm{ul}$ chromatin was used for immunoprecipitation by anti-Flag antibodies (F1804, Sigma) and IgG antibodies (ab171870, Abcam) respectively. $10 \mu \mathrm{g}$ of antibody was used in the immunoprecipitation reactions at $4{ }^{\circ} \mathrm{C}$ overnight. The next day, $30 \mu \mathrm{L}$ of protein beads were added and the samples were further 
bioRxiv preprint doi: https://doi.org/10.1101/2021.11.05.467437; this version posted November 6, 2021. The copyright holder for this preprint (which was not certified by peer review) is the author/funder, who has granted bioRxiv a license to display the preprint in perpetuity. It is made available under aCC-BY-NC 4.0 International license.

incubated for $3 \mathrm{~h}$. Next, the beads were washed once with $20 \mathrm{mM}$ Tris/HCL (pH 8.1), $50 \mathrm{mM}$ $\mathrm{NaCl}, 2 \mathrm{mM}$ EDTA, 1\% Triton X-100, 0.1\% SDS; twice with $10 \mathrm{mM}$ Tris/HCL (pH 8.1), $250 \mathrm{mM}$ $\mathrm{LiCl}, 1 \mathrm{mM}$ EDTA, 1\% NP-40, 1\% deoxycholic acid; and twice with TE buffer $1 \times(10 \mathrm{mM}$ Tris-Cl at $\mathrm{pH} 7.5+1 \mathrm{mM}$ EDTA). Bound material was then eluted from the beads in $300 \mu \mathrm{L}$ of elution buffer ( $100 \mathrm{mM} \mathrm{NaHCO}_{3}, 1 \% \mathrm{SDS}$ ), treated first with RNase A (final concentration $8 \mu \mathrm{g} / \mathrm{mL}$ ) during $6 \mathrm{~h}$ at $65^{\circ} \mathrm{C}$ and then with proteinase $\mathrm{K}$ (final concentration $345 \mu \mathrm{g} / \mathrm{mL}$ ) overnight at $45^{\circ} \mathrm{C}$. To examine the quality of ChIP DNA to assess enrichment for PHR2 binding motif P1BS, a ChIPqPCR was conducted, using immunoprecipitated (anti-Flag and IgG) DNA and input DNA and specific primers for sequence flanking the P1BS motif in the IPS1 promoter. qPCR reactions were run using the ChamQ SYBR Color qPCR Master Mix (Vazyme Biotech, China) on Bio-RAD CFX384 real-time system (BioRad, USA). The enrichment values were normalized to the input sample. After normalizing with input, fold enrichment was calculated using the " $\Delta \Delta \mathrm{C}_{\mathrm{t}}$ " method by comparing with IgG negative control immunoprecipitated sample. Only samples showing more than 5-fold enrichment compared to IgG for the IPS1 promote $^{17}$ negative control were used for sequencing. For ChIP-Seq, immunoprecipitated and input DNA were used to construct sequencing libraries following the protocol provided by the NEXTflex® ChIP-Seq Library Prep Kit for Illumina ${ }^{\circledR}$ Sequencing (NOVA-5143, Bioo Scientific) and sequenced on HiSeq X Ten (Illumina, USA) with PE 150 method.

\section{ChIP-Seq Data analysis}

Sequencing yielded approximately 20 million paired-end reads of $150 \mathrm{bp}$ per sample. Quality control of raw reads was performed in FASTQC. Adaptor trimming was carried out with TRIMGalore (https://github.com/FelixKrueger/TrimGalore) followed by mapping to reference genome in BWA-MEM2 ${ }^{53}$. MACS2 was used to identify narrow or broad peaks representing PHR2 binding sites (showing enrichment of FLAG-immunoprecipitated sequencing reads over input sequencing reads) from non-duplicated uniquely mapped reads ${ }^{54}$. Peaks were extracted with a threshold of 1.5-fold enrichment over INPUT and significance $p$-value $\leq 0.05$. Fasta sequence for PHR2 binding sites and peak annotation to nearby genes were performed in samtools and bedtools respectively ${ }^{55,56}$. Read counts were normalized to CPM (Counts per Million mapped reads) and coverage was generated in deepTools2 and visualized with IGV 2.8.957,58. Motif enrichment analysis for PHR2 binding sites was carried out in STREME (https://memesuite.org/meme/tools/streme). Motif enrichment analysis for Set A + Set B genes in Fig. 3A was carried out in RSAT-oligo-analysis (http://rsat.eead.csic.es/plants/oligo-analysis form.cgi) ${ }^{59}$. GO enrichment on Set A + Set B genes was performed in AgriGO. The search for P1BS or P1BS-like motifs in the sequences 3000 bp regions (upstream of TSS) for PHR2 target genes identified in the two ChIP-Seq replicates separately and for genes with repression in phr2, was performed with RSAT-dna-pattern (http://rsat.eead.csic.es/plants/dna-pattern form.cgi).

\section{ChIP-qPCR}

ChIP was performed as mentioned above. Input DNA and FLAG- and IgG-immunoprecipitated DNA from 3 independent ChIP experiments were used for qPCR. QPCR was conducted with primers indicated in Table S2 and TransScript $₫$ Green qRT-PCR SuperMix (TransGen Biotech, Beijing, China) on a Bio-Rad CFX384 qPCR cycler (Bio-Rad Laboratories, Shanghai, China).

\section{GR24 treatment}

Plants inoculated with 500 spores of $R$. irregularis as described above were treated with a synthetic analogue of strigolactone, rac-GR24 (Chiralix, CX23880). rac-GR24 was dissolved at $10 \mathrm{mM}$ concentration in $100 \%$ acetone to make stocks and directly added to the Hoagland medium for use at 10 and $100 \mathrm{nM}$ concentrations. The control solution was supplied with equal amounts of acetone. Plants were watered 2 times per week for 6 weeks. At 6 weeks, roots were harvested for acid-ink staining and quantification of colonization. 
bioRxiv preprint doi: https://doi.org/10.1101/2021.11.05.467437; this version posted November 6, 2021. The copyright holder for this preprint (which was not certified by peer review) is the author/funder, who has granted bioRxiv a license to display the preprint in perpetuity. It is made available under aCC-BY-NC 4.0 International license.

\section{Plasmid construction}

Genes and promoter regions were amplified with NEB Q5 polymerase from cDNA or genomic DNA of wild type ( $\mathrm{cv}$. Nipponbare), according to standard protocols and using primers indicated in Table S3. Plasmids were constructed using Golden Gate cloning as described before ${ }^{60}$ and as indicated in Table S4.

\section{Transactivation assay}

Transactivation assays in N.benthamiana leaves were performed as described before ${ }^{61}$.

\section{Root exudate collection}

Dehusked rice seeds were surface sterilized by incubating in absolute Ethanol for 2 min, then immersing twice in $3.5 \%$ Sodium hypochlorite solution for 15 min and rinsing three times with demineralized sterile water (15 min per rinse). Seeds were germinated on $1.5 \% 1 / 2 \mathrm{MS}$-agar at $22^{\circ} \mathrm{C}$ in darkness for 1 week. Subsequently, germinated seedlings were exposed to light and grown for two weeks in a long-day photoperiod (16h light/8h dark) with $60 \%$ relative humidity in the same temperature conditions. Two seedlings were transferred to $7 \times 7 \times 8 \mathrm{~cm}$ pots filled with autoclaved sand (seven replicates of two seedlings per genotype). The plants were grown for 3 weeks in a chamber set at $22^{\circ} \mathrm{C}$ in a long-day photoperiod (16h light $/ 8 \mathrm{~h}$ dark) with $60 \%$ relative humidity. Each pot was supplied with demineralized sterile water for two weeks and then with 1/2 Hoagland's solution containing $25 \mu \mathrm{M}$ phosphate for one week. Root exudates were collected by adding and draining $150 \mathrm{~mL}$ water (containing 5\% ethanol) through each pot. The exudates were frozen using liquid nitrogen and stored at $-80^{\circ} \mathrm{C}$ until use.

\section{Strigolactone quantification}

Isolation of strigolactones from root exudates was carried out as reported previously ${ }^{24}$. The analyte 4-deoxyorobanchol and the internal standard rac-GR24 were obtained from Olchemim (Olomouc, Czech Republic). The extracts were analyzed on a QTrap 6500+ mass spectrometer (Sciex, Darmstadt, Germany) operating in the positive electrospray ionization (ESI+) mode. The following ESI source parameters were used: ion spray voltage $(5500 \mathrm{~V})$, source temperature $\left(550^{\circ} \mathrm{C}\right)$, turbo gas $(55 \mathrm{psi})$, heater gas $(65 \mathrm{psi})$. MS/MS analysis was performed in the multiple reaction monitoring (MRM) mode and individual MS parameters were optimized by collisioninduced dissociation after individually infusing the pure references (rac-GR24, 4-deoxyorobanchol) or the exudate extract (putative methoxy-5-deoxy strigol isomers) via a syringe pump into the mass spectrometer. For compound quantification, the specific mass transition of 4deoxyorobanchol $(331.0 \rightarrow 185.0)$, putative methoxy-5-deoxy strigol isomers $(361.0 \rightarrow 97.0$ ), and internal standard rac-GR24 $(299.0 \rightarrow 96.9)$ were used. The exudate extracts were separated on an ExionLC UHPLC system (Shimadzu, Duisburg, Germany), equipped with two ExionLC AD pump systems, an ExionLC degasser, an ExionLC AD autosampler, an ExionLC AD column oven and an ExionLC controller. Chromatographic separation was performed at a flow rate of 0.45 $\mathrm{mL} / \mathrm{min}$ on $100 \times 2.1 \mathrm{~mm}, 100 \AA, 1.7 \mu \mathrm{m}$ Kinetex C18 column (Phenomenex, Aschaffenburg, Germany) at $45^{\circ} \mathrm{C}$. The solvents used for chromatography were aqueous formic acid $(0.1 \%)$ as eluent $\mathrm{A}$ and acetonitrile ( $0.1 \%$ formic acid) as eluent $\mathrm{B}$. The following gradient was used based on reports from the literature ${ }^{24}$ with slight modifications: $0.0-1.0 \mathrm{~min}(15 \% \mathrm{~B}), 1.0-5.0 \mathrm{~min}(40 \%$ B), 5.0 - $8.0 \min (65 \% \mathrm{~B}), 8.0-9.0 \mathrm{~min}(65 \% \mathrm{~B}), 9.0-10.0 \min (100 \% \mathrm{~B}), 10.0-11.0 \min (100 \%$ B), 11.0 - 12.0 min (15\% B), 12.0 - 13.0 min (15\% B). The Analyst software (version 1.6.3) was used for data acquisition and processing.

\section{Phylogenetic analysis of PHR proteins}

Arabidopsis AtPHR1 was used to find close homologs in other plant species. Following this, Clustal Omega (https://www.ebi.ac.uk/Tools/msa/clustalo/) was used for multiple sequence alignment (MSA) of amino acid sequences for PHR proteins and homologous MYB TFs from AM- 
bioRxiv preprint doi: https://doi.org/10.1101/2021.11.05.467437; this version posted November 6, 2021. The copyright holder for this preprint (which was not certified by peer review) is the author/funder, who has granted bioRxiv a license to display the preprint in perpetuity. It is made available under aCC-BY-NC 4.0 International license.

incompetent species (Arabidopsis thaliana and Brassica rapa), monocotyledon AM-host species (Oryza sativa, Zea mays, and Sorghum bicolor) and dicotyledon AM-host species (Lotus japonicus, Medicago truncatula, and Solanum lycopersicum).

Based on the MSA, a tree was constructed using "Minimum evolution with 1000 bootstrap" in MEGA (https://www.megasoftware.net/). This tree was further modified in MEGA using "Maximum likelihood".

\title{
Greenhouse experiment
}

The soil was collected from a rice field at Longhua base in Shenzhen, China, which was inundated for a long period and then land-prepared prior to rice seeding. A long-inundated and landprepared field was chosen to ensure soil with very low amounts of infective AM fungal propagules ${ }^{41,62,63}$. The soil properties were as follows: $\mathrm{pH} 5.5$, total nitrogen $1.73 \mathrm{~g} \cdot \mathrm{kg}^{-1}$, total phosphorus $0.72 \mathrm{~g} \cdot \mathrm{kg}^{-1}$, total potassium $29.3 \mathrm{~g} \cdot \mathrm{kg}^{-1}$, organic carbon $22.5 \mathrm{~g} \cdot \mathrm{kg}^{-1}$, alkali hydrolysable nitrogen $216 \mathrm{mg} \cdot \mathrm{kg}^{-1}$, Olsen phosphorus $36.7 \mathrm{mg} \cdot \mathrm{kg}^{-1}$, available potassium 115.0 $\mathrm{mg} \cdot \mathrm{kg}^{-1}$. The experiment was conducted in the greenhouse of Shenzhen Research Institute, Chinese University of Hong Kong, Shenzhen, Guangdong, China $\left(22^{\circ} 32\right.$ 'N, $113^{\circ} 56$ 'E). The temperature, sunlight, and humidity of the greenhouse used in the experiment are shown in Fig. S16. Rice seeds were germinated and grown for 2 weeks on MS-agar. The seedlings were then transplanted to pots (each plant was put into a $4 \mathrm{~cm} \mathrm{X} 4 \mathrm{~cm}$ area and $15 \mathrm{~cm}$ height pot) filled with collected field soil and were mock-inoculated or inoculated with $R$. irregularis (1500 spores; Agronutrition, Toulouse, France). Pure AMF spores (applied to a thin quartz sand layer) were placed at the depth of $2.5 \mathrm{~cm}$ from the soil surface in inoculated samples while for non-inoculated samples only a thin sand layer was included. Plants were grown in a greenhouse at around 22 to $32^{\circ} \mathrm{C}$ (Fig. S16) till 110 days post transplanting (dpt) and irrigated with tap water once surface soil dried so that the water layer of $2 \sim 3 \mathrm{~cm}$ got restored. All plants were fertilized once with urea (100 $\mathrm{mg}$ per pot) and potash (75 mg per pot) at $40 \mathrm{dpt}$ before panicle initiation. HP samples were fertilized with superphosphate fertilizer, $\mathrm{P}_{2} \mathrm{O}_{5}$ at $75 \mathrm{mg} /$ pot (every 20 days) while LP plants were not fertilized with superphosphate at all. Plants reached the panicle initiation stage at around 40$45 \mathrm{dpt}$ and flowering started at around 75-80 dpt. At 110 days post transplanting, plant height and panicle length were determined and roots were harvested for quantification of root fresh weight, AM colonization, and gene expression analysis by RT-qPCR. Plants were air-dried for 1 week and quantified for shoot dry weight, seed setting (percentage of filled grains per total grains) and 1000 grain weight ([total grain weight per plant/total no. of grains per plant] * 1000). Further, shoots were oven-dried at $80^{\circ} \mathrm{C}$ and ground to powder for shoot phosphorus determination according to the previous description ${ }^{64}$.

\section{Statistics and graphics}

Data were statistically analyzed and presented graphically using $\mathrm{R}$ statistical environment (https://cran.r-project.org/) or Prism 8.0 (GraphPad, USA), respectively.

\author{
Data availability \\ RNAseq Data is submitted to BioProject PRJNA735781: \\ https://Dataview.ncbi.nlm.nih.gov/object/PRJNA735781?reviewer=3cvg1gepckl1es04rfuslpiad2 \\ ChIP-Seq Data is submitted to BioProject PRJNA735744: \\ https://Dataview.ncbi.nlm.nih.gov/object/PRJNA735744?reviewer=hjvlce636jnenf75q90rcce5a0
}




\section{References}

1 Chiu, C. H. \& Paszkowski, U. Mechanisms and impact of symbiotic phosphate acquisition. Cold Spring Harbor Perspectives in Biology 11, a034603, doi:10.1101/cshperspect.a034603 (2019).

2 Gianinazzi, S. et al. Agroecology: the key role of arbuscular mycorrhizas in ecosystem services. Mycorrhiza 20, 519-530, doi:10.1007/s00572-010-0333-3 (2010).

3 Smith, S. E., Smith, F. A. \& Jakobsen, I. Mycorrhizal fungi can dominate phosphate supply to plants irrespective of growth responses. Plant Physiology 133, 16-20, doi:10.1104/pp.103.024380 (2003).

4 Balzergue, C., Chabaud, M., Barker, D. G., Bécard, G. \& Rochange, S. F. High phosphate reduces host ability to develop arbuscular mycorrhizal symbiosis without affecting root calcium spiking responses to the fungus. Frontiers in Plant Science 4, 426, doi:10.3389/fpls.2013.00426 (2013).

$5 \quad$ Breuillin, F. et al. Phosphate systemically inhibits development of arbuscular mycorrhiza in Petunia hybrida and represses genes involved in mycorrhizal functioning. Plant Journal 64, 1002-1017, doi:10.1111/j.1365-313X.2010.04385.x (2010).

$6 \quad$ Kobae, Y. et al. Phosphate treatment strongly inhibits new arbuscule development but not the maintenance of arbuscule in mycorrhizal rice roots. Plant Physiology 171, 566-579, doi:10.1104/pp.16.00127 (2016).

7 Rouached, H., Arpat, A. B. \& Poirier, Y. Regulation of phosphate starvation responses in plants: signaling players and cross-talks. Molecular Plant 3, 288-299, doi:https://doi.org/10.1093/mp/ssp120 (2010).

8 Rubio, V. et al. A conserved MYB transcription factor involved in phosphate starvation signaling both in vascular plants and in unicellular algae. Genes \& Development 15, $2122-$ 2133, doi:10.1101/gad.204401 (2001).

9 Bustos, R. et al. A central regulatory system largely controls transcriptional activation and repression responses to phosphate starvation in Arabidopsis. PLOS Genetics 6, e1001102- (2010).

10 Chen, A. et al. Identification of two conserved cis-acting elements, MYCS and P1BS, involved in the regulation of mycorrhiza-activated phosphate transporters in eudicot species. New Phytologist 189, 1157-1169, doi:10.1111/j.1469-8137.2010.03556.x (2011).

11 Lota, F. et al. The cis-acting CTTC-P1BS module is indicative for gene function of LjVTI12, a $\mathrm{Qb}-\mathrm{SNARE}$ protein gene that is required for arbuscule formation in Lotus japonicus. The Plant Journal 74, 280-293, doi:10.1111/tpj.12120 (2013).

12 Xue, L. et al. AP2 transcription factor CBX1 with a specific function in symbiotic exchange of nutrients in mycorrhizal Lotus japonicus. Proceedings of the National Academy of Sciences U.S.A 115, E9239-E9246, doi:10.1073/PNAS.1812275115 (2018).

13 Carbonnel, S. \& Gutjahr, C. Control of arbuscular mycorrhiza development by nutrient signals. Frontiers in Plant Science 5, 462 (2014).

14 Gutjahr, C. et al. Arbuscular mycorrhiza-specific signaling in rice transcends the common symbiosis signaling pathway. The Plant Cell 20, 2989-3005, doi:10.1105/tpc.108.062414 (2008).

15 Guo, M. et al. Integrative comparison of the role of the PHOSPHATE RESPONSE1 subfamily in phosphate signaling and homeostasis in rice. Plant Physiology 168, $1762-$ 1776, doi:10.1104/pp.15.00736 (2015).

16 Ruan, W., Guo, M., Wu, P. \& Yi, K. Phosphate starvation induced OsPHR4 mediates Pisignaling and homeostasis in rice. Plant Molecular Biology 93, 327-340, doi:10.1007/s11103-016-0564-6 (2017).

17 Wang, Z. et al. Rice SPX1 and SPX2 inhibit phosphate starvation responses through interacting with PHR2 in a phosphate-dependent manner. Proceedings of the National Academy of Sciences U.S.A 111, 14953-14958, doi:10.1073/pnas.1404680111 (2014). 
bioRxiv preprint doi: https://doi.org/10.1101/2021.11.05.467437; this version posted November 6,2021 . The copyright holder for this preprint (which was not certified by peer review) is the author/funder, who has granted bioRxiv a license to display the preprint in perpetuity. It is made available under aCC-BY-NC 4.0 International license.

$18 \mathrm{Hu}, \mathrm{B}$. et al. Nitrate-NRT1.1B-SPX4 cascade integrates nitrogen and phosphorus signalling networks in plants. Nature Plants 5, 401-413, doi:10.1038/s41477-019-0384-1 (2019).

19 Miura, K. et al. The Arabidopsis SUMO E3 ligase SIZ1 controls phosphate deficiency responses. Proceedings of the National Academy of Sciences U.S.A 102, 7760-7765, doi:10.1073/pnas.0500778102 (2005).

20 Shi, J. et al. A phosphate starvation response-centered network regulates mycorrhizal symbiosis. Cell 184, 5527-5540.e5518, doi:10.1016/j.cell.2021.09.030 (2021).

21 Fiorilli, V., Wang, J. Y., Bonfante, P., Lanfranco, L. \& Al-Babili, S. Apocarotenoids: old and new mediators of the arbuscular mycorrhizal symbiosis. Frontiers in Plant Science 10, 1186 (2019).

22 MacLean, A. M., Bravo, A. \& Harrison, M. J. Plant signaling and metabolic pathways enabling arbuscular mycorrhizal symbiosis. The Plant Cell 29, 2319-2335, doi:10.1105/tpc.17.00555 (2017).

23 Bravo, A., York, T., Pumplin, N., Mueller, L. A. \& Harrison, M. J. Genes conserved for arbuscular mycorrhizal symbiosis identified through phylogenomics. Nature Plants 2, 15208, doi:10.1038/nplants.2015.208 (2016).

24 Choi, J. et al. The negative regulator SMAX1 controls mycorrhizal symbiosis and strigolactone biosynthesis in rice. Nature Communications 11, 2114, doi:10.1038/s41467020-16021-1 (2020).

25 Gutjahr, C. et al. Rice perception of symbiotic arbuscular mycorrhizal fungi requires the karrikin receptor complex. Science (New York, N.Y.) 350, 1521 - 1524 (2015).

26 Mehra, P., Pandey, B. K., Verma, L. \& Giri, J. A novel glycerophosphodiester phosphodiesterase improves phosphate deficiency tolerance in rice. Plant, Cell \& Environment 42, 1167-1179 (2019).

27 Wang, Z. et al. Regulation of OsSPX1 and OsSPX3 on expression of OsSPX domain genes and Pi-starvation signaling in rice. Journal of Integrative Plant Biology 51, 663-674, doi:10.1111/j.1744-7909.2009.00834.x (2009).

28 Fiorilli, $V$. et al. A rice GRAS gene has an impact on the success of arbuscular mycorrhizal colonization. American Journal of Plant Sciences 6, 1905-1915 (2015).

29 Yoneyama, K., Xie, X., Kisugi, T., Nomura, T. \& Yoneyama, K. Nitrogen and phosphorus fertilization negatively affects strigolactone production and exudation in sorghum. Planta 238, 885-894 (2013).

30 Akiyama, K., Matsuzaki, K.-i. \& Hayashi, H. Plant sesquiterpenes induce hyphal branching in arbuscular mycorrhizal fungi. Nature 435, 824-827 (2005).

31 Gutjahr, C. et al. The half-size ABC transporters STR1 and STR2 are indispensable for mycorrhizal arbuscule formation in rice. The Plant Journal 69, 906-920 (2012).

32 Kobae, Y. et al. Strigolactone biosynthesis genes of rice are required for the punctual entry of arbuscular mycorrhizal fungi into the roots. Plant and Cell Physiology 59, 544-553 (2018).

33 Yoshida, S. et al. The D3 F-box protein is a key component in host strigolactone responses essential for arbuscular mycorrhizal symbiosis. New Phytologist 196, 1208-1216 (2012).

34 Floss, D. S., Schliemann, W., Schmidt, J., Strack, D. \& Walter, M. H. RNA interferencemediated repression of MtCCD1 in mycorrhizal roots of Medicago truncatula causes accumulation of $\mathrm{C} 27$ apocarotenoids, shedding light on the functional role of CCD1. Plant Physiology 148, 1267-1282 (2008).

35 Pimprikar, P. et al. A CCaMK-CYCLOPS-DELLA complex activates transcription of RAM1 to regulate arbuscule branching. Current Biology 26, 987-998 (2016).

36 Nouri, E. et al. Phosphate suppression of arbuscular mycorrhizal symbiosis involves gibberellic acid signaling. Plant and Cell Physiology 62, 959-970 (2021). 
bioRxiv preprint doi: https://doi.org/10.1101/2021.11.05.467437; this version posted November 6,2021 . The copyright holder for this preprint (which was not certified by peer review) is the author/funder, who has granted bioRxiv a license to display the preprint in perpetuity. It is made available under aCC-BY-NC 4.0 International license.

37 Małolepszy, A. et al. The LORE1 insertion mutant resource. The Plant Journal 88, 306317, doi:10.1111/tpj.13243 (2016).

38 Barragán-Rosillo, A. C. et al. Genome accessibility dynamics in response to phosphate limitation is controlled by the PHR1 family of transcription factors in Arabidopsis. Proc NatI Acad Sci U S A 118, e2107558118, doi:10.1073/pnas.2107558118 (2021).

39 Miyata, K. et al. The bifunctional plant receptor, OsCERK1, regulates both chitin-triggered immunity and arbuscular mycorrhizal symbiosis in rice. Plant and Cell Physiology 55, 1864-1872 (2014).

$40 \mathrm{He}$, J. et al. A LysM receptor heteromer mediates perception of arbuscular mycorrhizal symbiotic signal in rice. Molecular Plant 12, 1561-1576 (2019).

41 Yang, S.-Y. et al. Nonredundant regulation of rice arbuscular mycorrhizal symbiosis by two members of the PHOSPHATE TRANSPORTER1 gene family. The Plant Cell 24, 4236-4251, doi:10.1105/tpc.112.104901 (2012).

42 Lv, Q. et al. SPX4 negatively regulates phosphate signaling and homeostasis through its interaction with PHR2 in rice. The Plant Cell 26, 1586-1597 (2014).

43 Wild, R. et al. Control of eukaryotic phosphate homeostasis by inositol polyphosphate sensor domains. Science (New York, N.Y.) 352, 986-990, doi:10.1126/science.aad9858 (2016).

44 Wang, P. et al. Medicago SPX1 and SPX3 regulate phosphate homeostasis, mycorrhizal colonization, and arbuscule degradation. The Plant cell, doi:10.1093/plcell/koab206 (2021).

45 Urbański, D. F., Małolepszy, A., Stougaard, J. \& Andersen, S. U. Genome-wide LORE1 retrotransposon mutagenesis and high-throughput insertion detection in Lotus japonicus. The Plant Journal 69, 731-741, doi:10.1111/j.1365-313X.2011.04827.x (2012).

46 Torabi, S., Varshney, K., Villaécija-Aguilar, J. A., Keymer, A. \& Gutjahr, C. in Methods Mol Biol. (Strigolactones: Methods and Protocols) Vol. 2309 (eds Cristina Prandi \& Francesca Cardinale) 157-177 (Springer Nature, Switzerland, 2021).

47 McGonigle, T. P., Miller, M. H., Evans, D. G., Fairchild, G. L. \& Swan, J. A. A new method which gives an objective measure of colonization of roots by vesicular-arbuscular mycorrhizal fungi. New Phytologist 115, 495-501 (1990).

48 Vierheilig, H., Coughlan, A. P., Wyss, U. \& Piche, Y. Ink and vinegar, a simple staining technique for arbuscular-mycorrhizal fungi. Applied and Environmental Microbiology 64, 5004-5007, doi:10.1128/aem.64.12.5004-5007.1998 (1998).

49 Czechowski, T., Bari, R. P., Stitt, M., Scheible, W. R. \& Udvardi, M. K. Real-time RT-PCR profiling of over 1400 Arabidopsis transcription factors: unprecedented sensitivity reveals novel root- and shoot-specific genes. The Plant Journal 38, 366-379, doi:10.1111/j.1365313X.2004.02051.x (2004).

50 Patro, R., Duggal, G., Love, M. I., Irizarry, R. A. \& Kingsford, C. Salmon provides fast and bias-aware quantification of transcript expression. Nature Methods 14, 417-419 (2017).

51 Tian, T. et al. agriGO v2.0: a GO analysis toolkit for the agricultural community, 2017 update. Nucleic Acids Research 45, W122-W129 (2017).

52 Vimont, N. et al. ChIP-seq and RNA-seq for complex and low-abundance tree buds reveal chromatin and expression co-dynamics during sweet cherry bud dormancy. Tree Genetics \& Genomes 16, 1-18 (2020).

53 Vasimuddin, M., Misra, S., Li, H. \& Aluru, S. in 2019 IEEE International Parallel and Distributed Processing Symposium (IPDPS) 314-324 (IEEE, 2019).

54 Zhang, Y. et al. Model-based analysis of ChIP-Seq (MACS). Genome Biology 9, 1-9 (2008).

55 Danecek, P. et al. Twelve years of SAMtools and BCFtools. GigaScience 10, giab008 (2021). 
bioRxiv preprint doi: https://doi.org/10.1101/2021.11.05.467437; this version posted November 6, 2021. The copyright holder for this preprint (which was not certified by peer review) is the author/funder, who has granted bioRxiv a license to display the preprint in perpetuity. It is made available under aCC-BY-NC 4.0 International license.

56 Quinlan, A. R. \& Hall, I. M. BEDTools: a flexible suite of utilities for comparing genomic features. Bioinformatics 26, 841-842 (2010).

57 Ramírez, F. et al. deepTools2: a next generation web server for deep-sequencing data analysis. Nucleic Acids Research 44, W160-W165 (2016).

58 Robinson, J. T. et al. Integrative genomics viewer. Nature Biotechnology 29, 24-26 (2011).

59 Nguyen, N. T. T. et al. RSAT 2018: regulatory sequence analysis tools 20th anniversary. Nucleic Acids Research 46, W209-W214 (2018).

60 Binder, A. et al. A modular plasmid assembly kit for multigene expression, gene silencing and silencing rescue in plants. PLOS One 9, e88218 (2014).

61 Singh, S., Katzer, K., Lambert, J., Cerri, M. \& Parniske, M. CYCLOPS, a DNA-binding transcriptional activator, orchestrates symbiotic root nodule development. Cell Host \& Microbe 15, 139-152 (2014).

62 Ilag, L. L., Rosales, A. M., Elazegui, F. A. \& Mew, T. W. Changes in the population of infective endomycorrhizal fungi in a rice-based cropping system. Plant and Soil 103, 6773 (1987).

63 Vallino, M., Fiorilli, V. \& Bonfante, P. Rice flooding negatively impacts root branching and arbuscular mycorrhizal colonization, but not fungal viability. Plant, Cell \& Environment 37 , 557-572 (2014).

64 Huang, R. et al. Natural variation at OsCERK 1 regulates arbuscular mycorrhizal symbiosis in rice. New Phytologist 225, 1762-1776 (2020).

65 Wang, J. Y. et al. The apocarotenoid metabolite zaxinone regulates growth and strigolactone biosynthesis in rice. Nature Communications 10, 1-9 (2019).

66 Stracke, S. et al. A plant receptor-like kinase required for both bacterial and fungal symbiosis. Nature 417, 959-962 (2002).

67 Zhang, X. et al. The receptor kinase CERK1 has dual functions in symbiosis and immunity signalling. The Plant Journal 81, 258-267 (2015).

68 Lauressergues, D. et al. The microRNA miR171h modulates arbuscular mycorrhizal colonization of Medicago truncatula by targeting NSP2. The Plant Journal 72, 512-522 (2012).

\section{Acknowledgments}

We thank Prof. Mao Chuanzao (Zhejiang University; Zhejiang, China) and Prof. Chengcai Chu (Chinese Academy of Sciences; Beijing, China) for the kind donation of seeds and Philipp Chapman (Gutjahr laboratory) for excellent technical support. The study was mainly funded by research grant 2020M672839 "Phosphate regulation of rice arbuscule mycorrhiza symbiosis" by the China Postdoctoral Science Foundation and a postdoc research grant from CUHK Shenzhen Research Institute to DD and by an ERC Starting Grant (759731) 'Regulatory networks of plant cell rearrangement during symbiont accommodation' to CG; by the CRC924 'Molecular mechanisms regulating yield and yield stability and plants' of the German Research Council (DFG) to CG (project B03) and CD (project B12); by the Natural Science Foundation of Jiangsu Province SBK2020042924 to MC; by Hong Kong Research Grant Council grant 14177617 to JZ and by Hong Kong Research Grant Council Area of Excellence Scheme grant AoE/M-403/16 to $\mathrm{HML}$ and JZ.

\section{Author contributions}

Conceptualization: DD, CG. Methodology: DD, MP, MG, CG. Investigation: DD, MP, KH, MG. Visualization: DD with input from CG. Funding acquisition: DD, CG, JZ, HML, CD. Project administration: DD, MC, CG, JZ, HML. Supervision: CG, MC, JZ. Writing - original draft: DD, CG, Writing - methods: DD, MP, KH, MG, CG. Writing - review \& editing: DD, CG. 
bioRxiv preprint doi: https://doi.org/10.1101/2021.11.05.467437; this version posted November 6, 2021. The copyright holder for this preprint (which was not certified by peer review) is the author/funder, who has granted bioRxiv a license to display the preprint in perpetuity. It is made available under aCC-BY-NC 4.0 International license.

\section{Competing interests}

The authors declare no conflicts of interest.

\section{Materials \& Correspondence}

Correspondence and material requests should be addressed to

C.G. (caroline.gutjahr@tum.de),

J.Z. (jzhang@hkbu.edu.hk) and

M.C. (cmx2009920734@gmail.com).

\section{Main figures}

Fig. 1. Effect of PHR2 mutation and overexpression on root colonization by AM fungi. Percent root length colonization (RLC) total (A), arbuscules (B), and vesicles (C) of the indicated genotypes inoculated with $R$. irregularis (AMF) for 7 weeks at low phosphate $(25 \mu \mathrm{M} \mathrm{P}, \mathrm{iP})$ or high phosphate $(500 \mu \mathrm{M} \mathrm{P}, \mathrm{HP})$. (D) Percent RLC of the indicated genotypes with AMF for 7 weeks at LP. Arb.: Arbuscules; Ves.: Vesicles. (E-F) Confocal images of AMF in roots wild type $(\mathbf{E})$ and phr2 (F) roots. (G-H) Arbuscule phenotype in wild type $(\mathbf{G})$ and phr2 $(\mathbf{H})$ roots. $\mathbf{E}$, extraradical hypha; $H$, hyphopodium; I, intraradical hypha; A, arbuscule. Scale-bars: D, E: 100 $\mu \mathrm{m}$ and F, G: $10 \mu \mathrm{m}$. Statistics: Individual data points and mean $\pm \mathrm{SE}$ are shown. (A-C) $\mathrm{N}=5$; Brown-forsythe and Welch's One-Way ANOVA test with Games-Howell's multiple comparisons test. Different letters indicate statistical differences between the samples. (D) $N=5$; Mann-Whitney test between phr2(C) and wild type within Total, Arb. and Ves. data-points. Asterisks denote significance of difference: ${ }^{* *} p \leq 0.01 ;{ }^{* *} p \leq 0.001$.

Fig. 2. The PHR2-dependent transcriptome of non-colonized roots contains genes required for AM development. (A) Number of up- and down-regulated differentially expressed genes (DEGs) in phr2 vs WT (LP) and 35S:PHR2 vs WT (HP) for mock or R. irregularis-inoculated plants. (B) PCA plot for the transcriptome of indicated samples. (C) Hierarchical clustering of combined DEGs from mock-inoculated roots using normalized counts. Colored bars on the left of the heatmap depict individual clusters (based on the dendrogram). Z-scores represent scaled normalized counts. (D) Mean $\log _{2} \mathrm{FC}$ of phr2 vs WT (LP) and 35S:PHR2 vs WT (HP) for clusters obtained in (C). Dotted lines indicate mean $\log _{2} \mathrm{FC}$ values of -0.585 and 0.585 (used as a cut-off for selecting DEGs). Dashed boxes highlight the mean $\log _{2} \mathrm{FC}$ of clusters with overall reduced transcript accumulation in phr2 vs WT. (E) Z-scores for a subset of genes from (C) previously reported being functionally required in AM. Asterisks represent a significant difference to the respective WT (FDR $\leq 0.05$ ). (F) Venn diagram showing overlap of DEGs with increased transcript accumulation in wild type 'AM vs Mock' and DEGs with reduced transcript accumulation in 'phr2 vs WT' in Mock at LP. (G) Venn diagram showing the intersection of DEGs with reduced transcript accumulation in the 'phr2 vs WT' comparison for mock and AMF-inoculated samples with AM genelist (Data S5) and DEGs upregulated in either smax1 (vs WT) or $d 3$ smax1 (vs WT) Mock ${ }^{24}$.

Fig. 3. PHR2 directly targets important AM symbiosis genes. (A) Overlap of PHR2 ChIP-Seq targets with RNASeq DEGs displaying reduced expression in Mock and AM roots of phr2 vs WT samples grown at LP and with AM genelist (Data S5). (B) Consensus PHR2-binding for Set A + Set B genes based on 'RSAT Plants' oligo-analysis. (C) Fold change of RNAseq-based transcript accumulation in Mock and AM roots of phr2 vs WT grown at LP (left) and ChIP-Seq fold enrichment for PHR2 binding (right) for the 15 Set B genes. Genes with assigned functional roles in AM based on mutant phenotypes are displayed in red (bold for mutants, regular font for RNAi lines). (D) Illustration of promoters used in transactivation assays with positions of $P 1 B S$ elements (black) and mutated P1BS elements (red). (E) PHR2 transactivates the promoters of GDPD2, CCD7, ZAS, and PT11 (553, 3540, 3377, 1590 bp upstream of ATG, respectively) in a P1BS 
element-dependent manner in Nicotiana benthamiana leaves. promoter:GUS fusions were cotransformed with 35S:PHR2 or 35S:mCherry (negative control). ' $\mathrm{m}$ ' indicates that all P1BS elements in the promoter were mutated. Individual dots show GUS activity in protein extracts from leaf discs from 4 independent plants. (F) Quantity of 4-deoxyorobanchol and two isomers of methoxy-5-deoxystrigol in the root exudates of WT, phr2, and 35S:PHR2 grown at LP. (G) Percent root length colonization total (left), arbuscules (middle), and vesicles (right) of the indicated genotypes inoculated with $R$. irregularis for 6 weeks at low phosphate $\left(25 \mu \mathrm{M} \mathrm{P} \mathrm{P}_{\mathrm{i}}\right)$ and treated with $0.02 \%$ acetone solvent or the synthetic SL analogue rac-GR24. (E-G) Individual data points and mean $\pm \mathrm{SE}$ are shown. (E) $\mathrm{N}=11-12$; Kruskal-Wallis test with Dunn's posthoc comparison. (F) N=6-7; Brown-Forsythe and Welch's One-Way ANOVA test with Games-Howell's multiple comparisons test. (G) $\mathrm{N}=5$; Brown-Forsythe and Welch's One-Way ANOVA test with Games-Howell's multiple comparisons test.

Fig. 4. PHR1A is required for full colonization of Lotus japonicus roots by $R$. irregularis (AC) Percent intraradical hyphae (A), arbuscules (B), and vesicles (C) of hairy roots for indicated genotypes inoculated with $R$. irregularis (AMF) for 4 weeks at $250 \mu \mathrm{M} \mathrm{P}_{\mathrm{i}}$ or $2500 \mu \mathrm{M} \mathrm{P}_{\mathrm{i}}$. EV, empty vector. (D) Relative transcript accumulation in mock-inoculated (Mock) hairy roots of the indicated genotypes in parallel with the experiment in Fig. 5A-C. Statistics: Individual data points and mean \pm SE are shown. (A-C) N=5-13; Brown-forsythe and Welch's One-Way ANOVA test with GamesHowell's multiple comparisons test. Different letters indicate statistical differences between the samples. (D) $\mathrm{N}=3$; Mann-Whitney test. Different letters indicate statistical differences between statistical groups.

Fig. 5. PHR2 affects AM-mediated phosphate uptake and yield in field soil. (A) Total shoot phosphorus (mg), (B) seed setting (C) 1000 grain weight of the indicated genotypes inoculated with $R$. irregularis (AM) or non-inoculated (Mock) and grown at LP (unfertilized) or HP (fertilized with superphosphate fertilizer, $\mathrm{P}_{2} \mathrm{O}_{5}$ ). Plants were grown in a greenhouse in soil from the Longhua field base in Shenzhen, China, and harvested at 110 days post transplanting (dpt). Statistics: Individual data points and mean \pm SE are shown. (A-C) $N=3-5$; Mann-Whitney test between mock and AM data points within each genotype sample at LP or HP. Asterisks denote significance of difference: ${ }^{*} p \leq 0.05 ;{ }^{* *} p \leq 0.01 ;{ }^{* * *} p \leq 0.001$.

\section{Fig. 6. Model depicting regulation of AM symbiosis by PHR2.}

When plants obtain sufficient phosphate (left), SPX proteins prevent nuclear translocation of $\mathrm{PHR}^{42}$ as well as PHR2 binding to promoters of phosphate starvation genes including AM relevant genes ${ }^{17,42}$. This causes low exudation of strigolactone and poor expression of genes required for perception of Myc-Factors and fungal entry, thereby preventing full symbiosis development. Upon phosphate starvation, SPX proteins, are degraded ${ }^{42}$. Consequently, PHR2 is active, can bind to P1BS elements in promoters, and transcriptionally activate genes important for AM, such as CCD7 involved in strigolactone biosynthesis for activation of the fungus in the rhizosphere prior to contact ${ }^{31-33}$, genes encoding receptors involved in the perception of fungal signals prior to root contact such as CERK1 and $S Y M R K^{39,40,66,67}$, the transcription factor $N S P 2^{68}$, ZAS involved in apocarotenoid biosynthesis promoting root colonization ${ }^{65}$, and the AM-specific phosphate transporter gene PT1141 (localized to the peri-arbuscular membrane (PAM)) required for $\mathrm{Pi}$ uptake from the fungus. (For simplicity, we focus here on 6 genes with important and genetically determined roles in AM that have been recovered in both ChIP-Seq replicates Fig. 3C, and were confirmed by ChIP-qPCR, Fig. S17). Consequently, at low phosphate, roots exude increased amounts of strigolactone and can perceive fungal signals (middle), the fungus is activated to colonize the roots and the symbiosis can function through nutrient transporters localizing to the peri-arbuscular membrane (right). Thus, symbiosis establishment appears to be enabled as a part of the PHR2-regulated phosphate starvation response. 
Figure 1

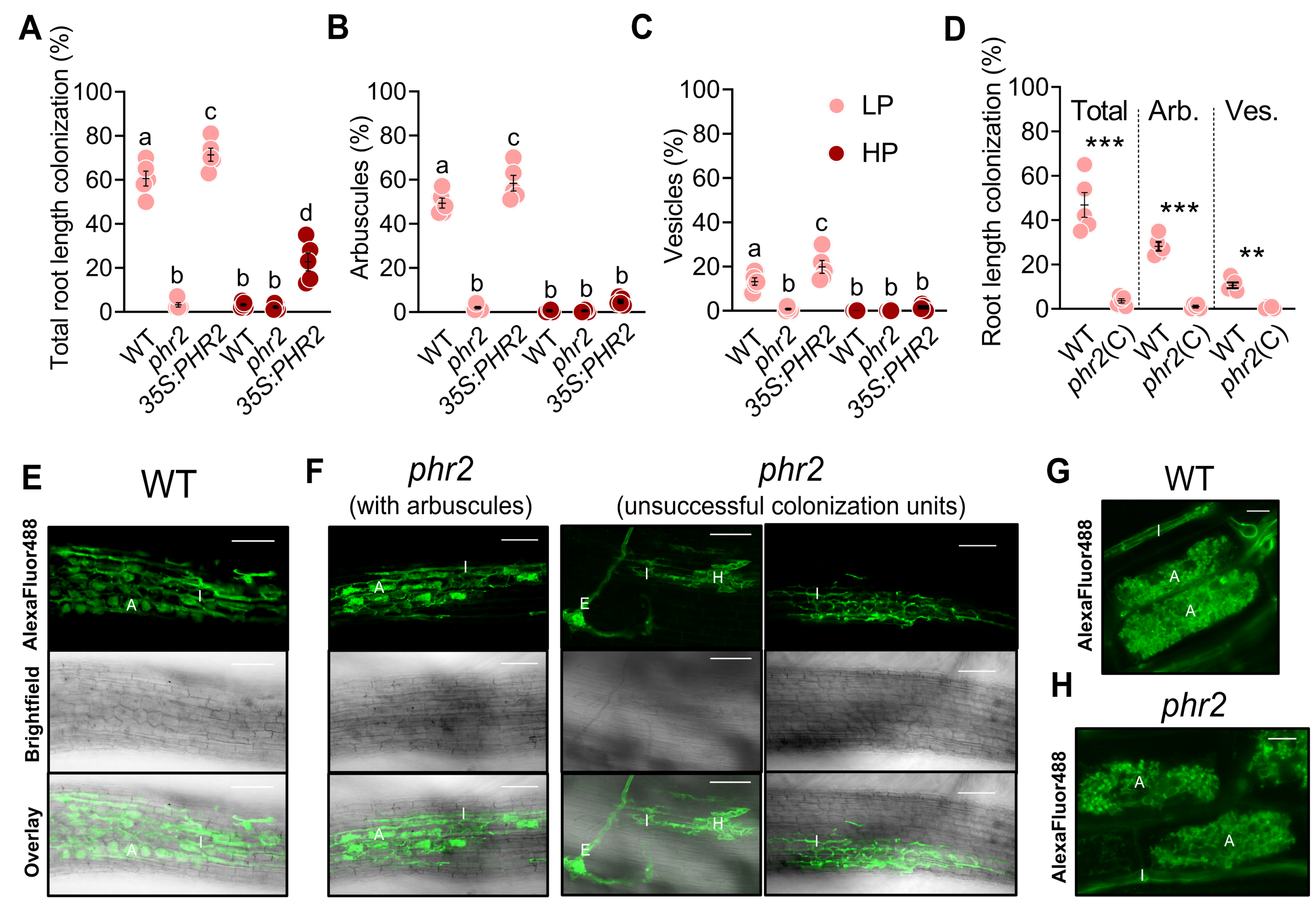




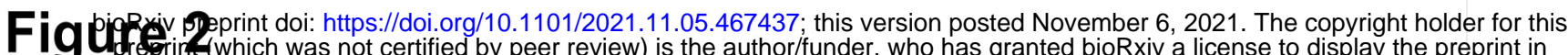
perpetuity. It is made available under aCC-BY-NC 4.0 International license.
palifed by peer review) is the author/funder, who has granted bioRxiv a licens

A

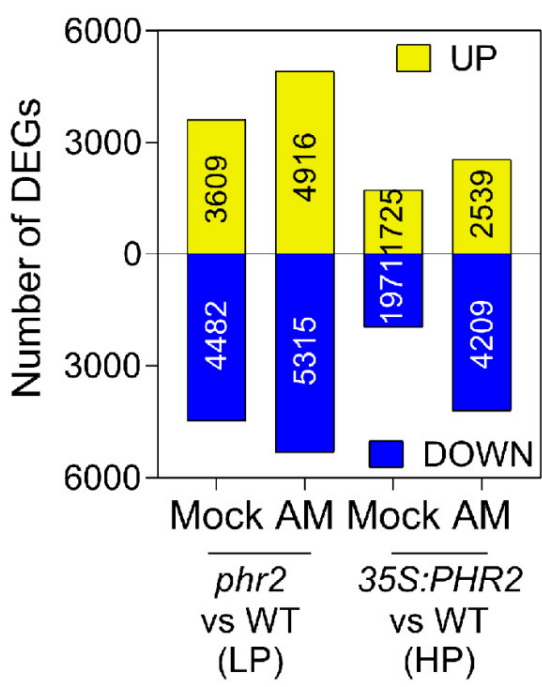

B

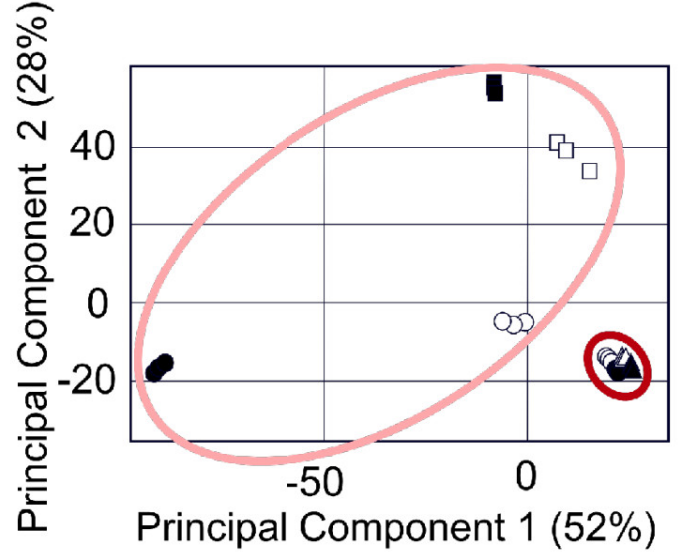

WT $\square$ Mock LP

$\square$ phr2

$\triangle$ 35S:PHR2

35S:PHR2 vs WT

HP Mock

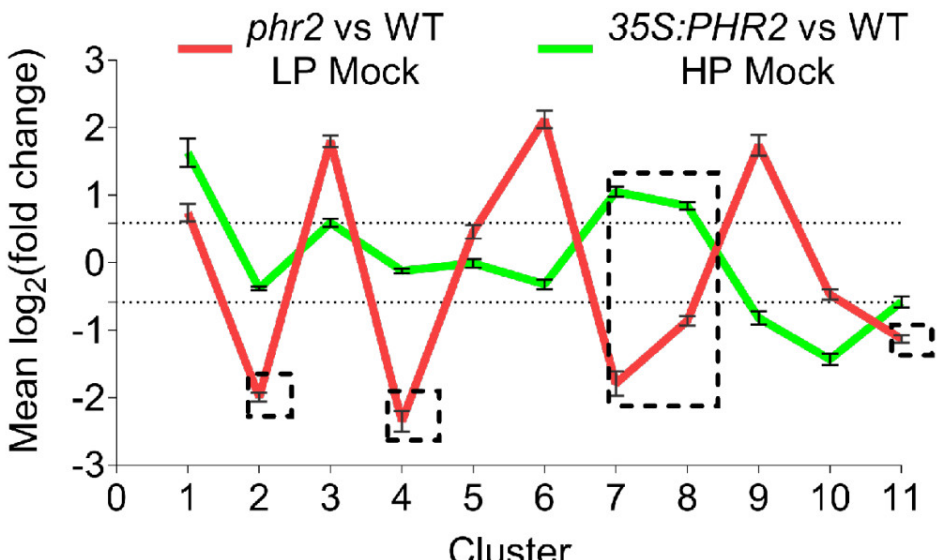

E

\begin{tabular}{|c|c|}
\hline * & \\
\hline$*$ & \\
\hline$\star$ & \\
\hline$*$ & \\
\hline * & \\
\hline$\star$ & \\
\hline * & \\
\hline * & \\
\hline * & \\
\hline * & \\
\hline * & \\
\hline$\star$ & * \\
\hline * & \\
\hline * & \\
\hline * & \\
\hline * & \\
\hline
\end{tabular}

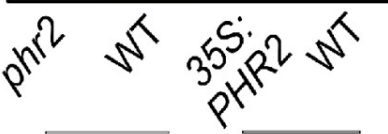

$\overline{\mathrm{LP}} \overline{\mathrm{HP}}$

Mock

\section{LOCUS ID CLUSTER GENE}

LOC_Os01g46860 2 PT11

LOC_Os03g13080 2 NFR5

LOC_Os03g15680 $2 \quad N S P 2$

LOC_Os03g29480 2 NSP1

LOC_Os03g45290 2 VAPYRIN

LOC_Os03g49990 $2 \quad$ SLR1

LOC_Os05g41090 2 CCaMK

LOC_Os05g51240 2 DLK2C

LOC_Os07g38070 2 SYMRK

LOC_Os06g44430 $5 \quad$ RLCK210 (KIN2)

LOC_Os09g23640 5 STR1

LOC_Os04g10800 $8 \quad$ PT13

LOC Os06g02520 8 CYCLOPS

LOC_Os01g54270 $11 \quad$ CCD8B

LOC_Os04g46470 $11 \quad$ CCD7

LOC_Os09g15240 11 ZAS

Z-score

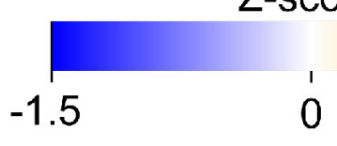

C

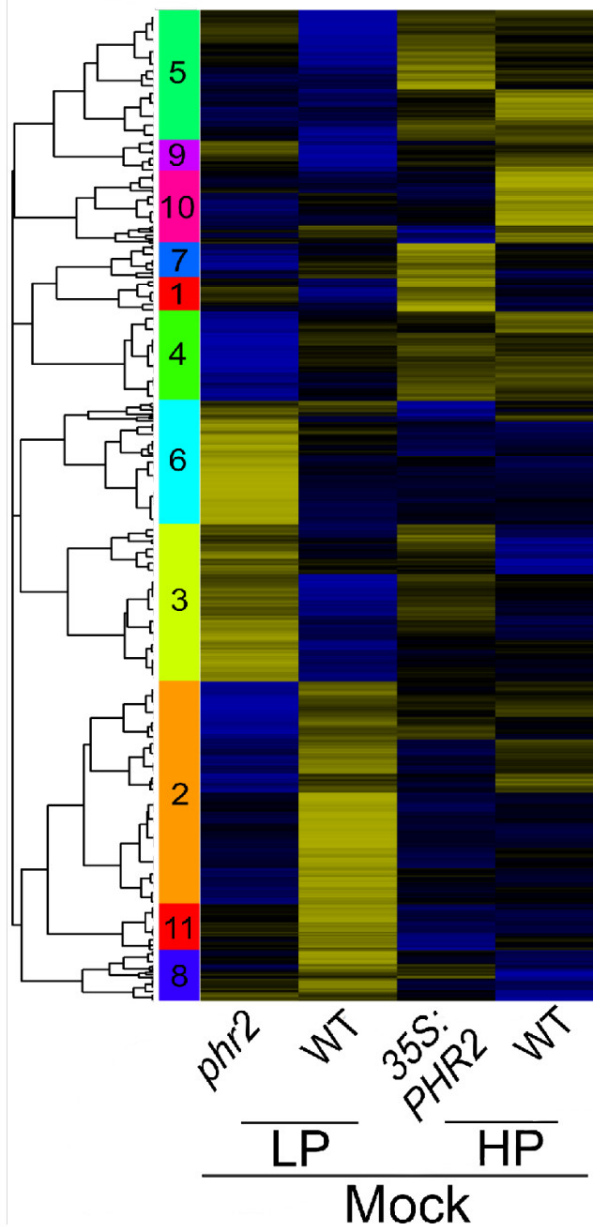

$\mathbf{F}$

WT AM vs Mock LP Up

phr2 vs WT Mock

LP Down
G

smax 1 or $d 3$ smax 1

vs WT Mock Up

(Choi et al., 2020) phr2 vs WT LP

$A M+$ Mock Down

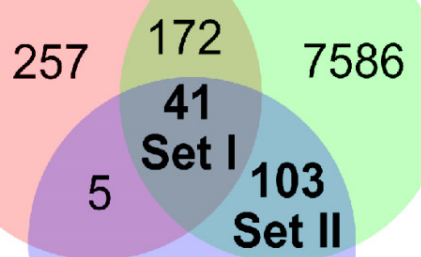

56

AM genelist 
A
ChIP-Seq
rep 2

phr2 vs WT LP

2279

6629

ChIP-Seq

rep 1

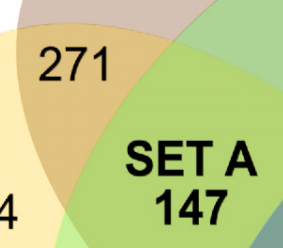

673

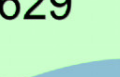

914

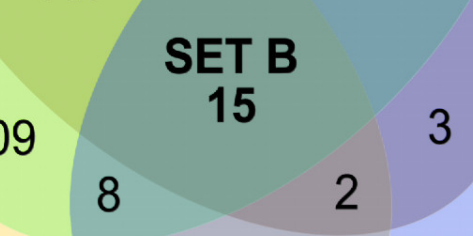

3

B

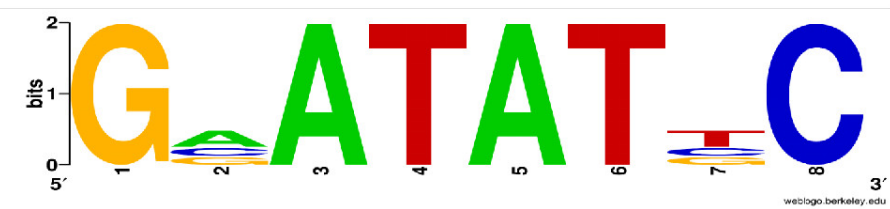

C

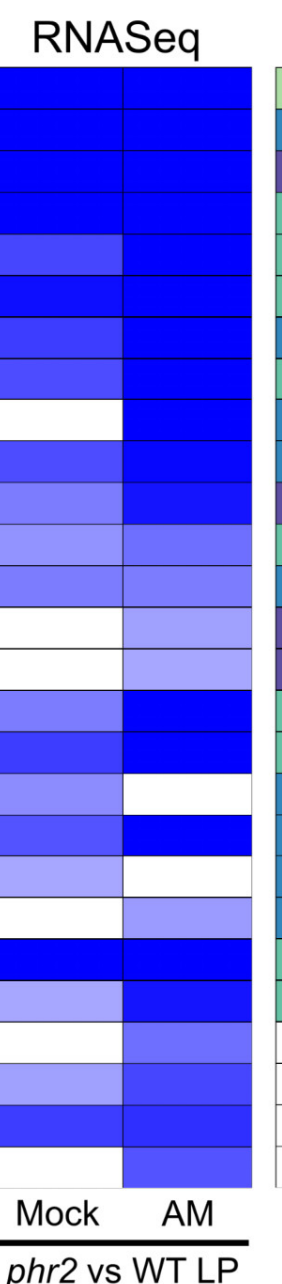

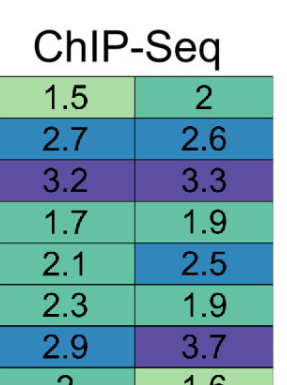

LOCUS ID

LS01g57400 AM3

LOC-Os06g44430 RLCK210 (MtKIN2)

LOC $^{-}$Os04g46470 CCD7

LOC-Os03g15680 NSP2

$\mathrm{LOC}^{-}$Os08g05690 ABCB20/MDR1

LOC-Os09g15240 ZAS

LOC $^{-} \mathrm{Os01955940}$ GH3.2

LOC_Os02g57700 PUB62, RLCK91

LOC_Os11g29630 Expressed protein

LOC_Os07g38070 SYMRK

LOC-Os06g50950 GELP90

LOC Os08g42580 CERK1

LOC-Os03g17310 ECA1 (MtMCA8)

LOC Os01g65000 AMT3;1

LOC-Os01g68130 Expressed protein

LOC-Os02g09960 LYK4

LOC-Os03g40080 AM18 (GRAS16)

LOC-Os03g49990 SLR

LOC-Os05g02020 RLCK176

LOC Os06g20120 AM11

LOC-Os08g42590 mtN19

LOC-Os04g55060 KAS III

LOC-Os06g02520 CYCLOPS

LOC ${ }^{-}$Os06g47130 NTMC2T1.5

LOC-Os08g15230 SMAX1

Rep 1 Rep 2

$\log _{2}$ (Fold-Change)
Fold enrichment

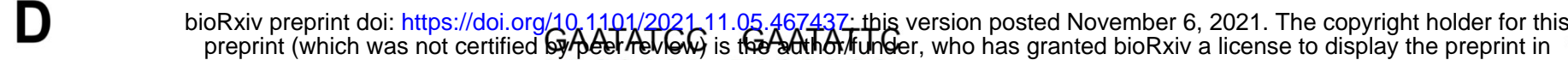

P1BS

Mutated P1BS

$$
553 \mathrm{bp} \text { GUS PGDPD2 }
$$

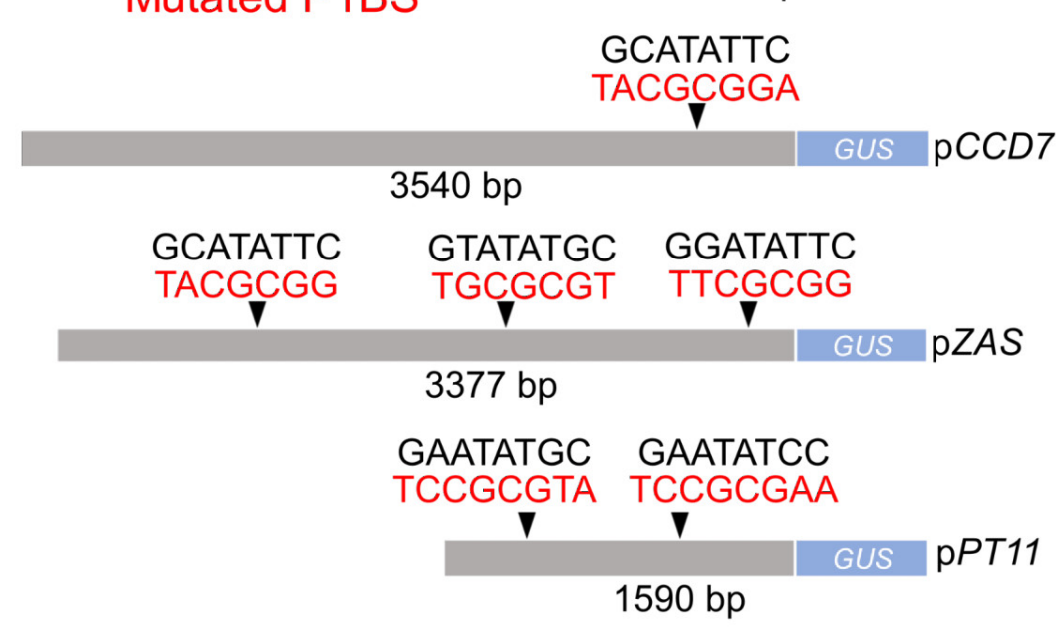

E

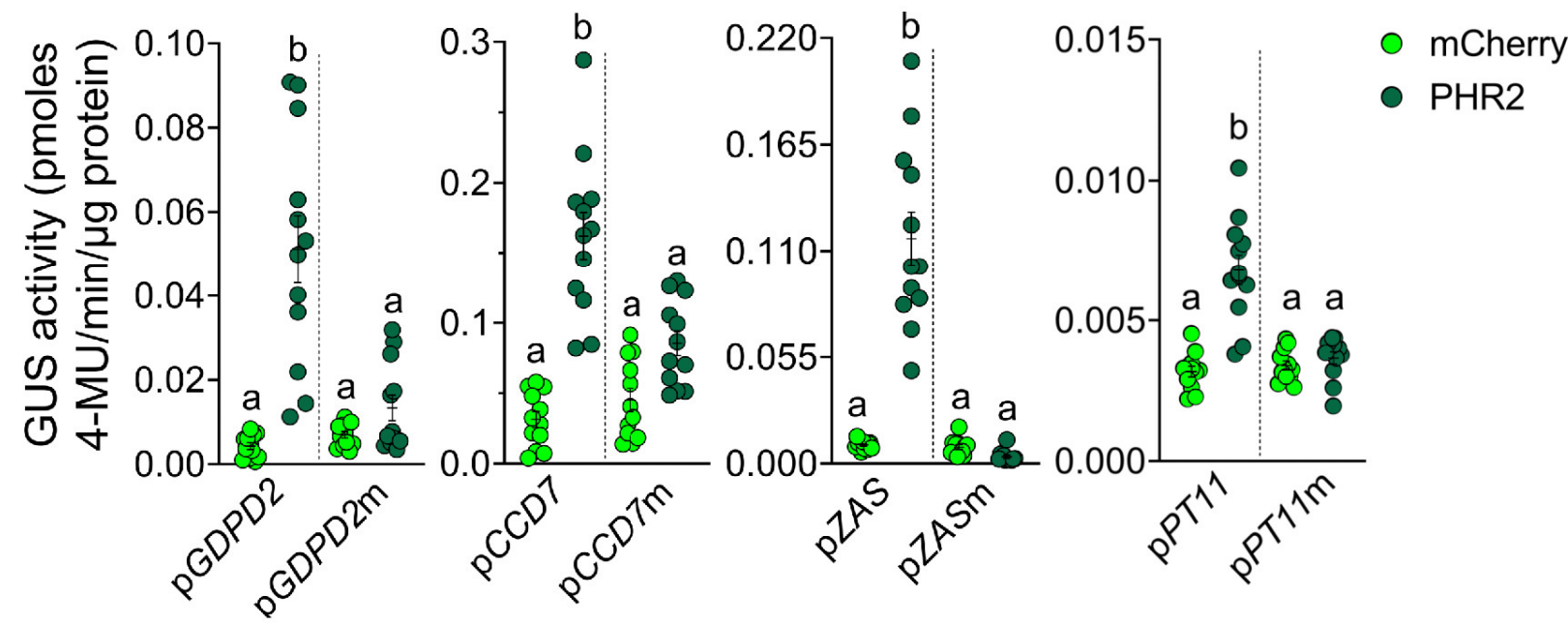

G
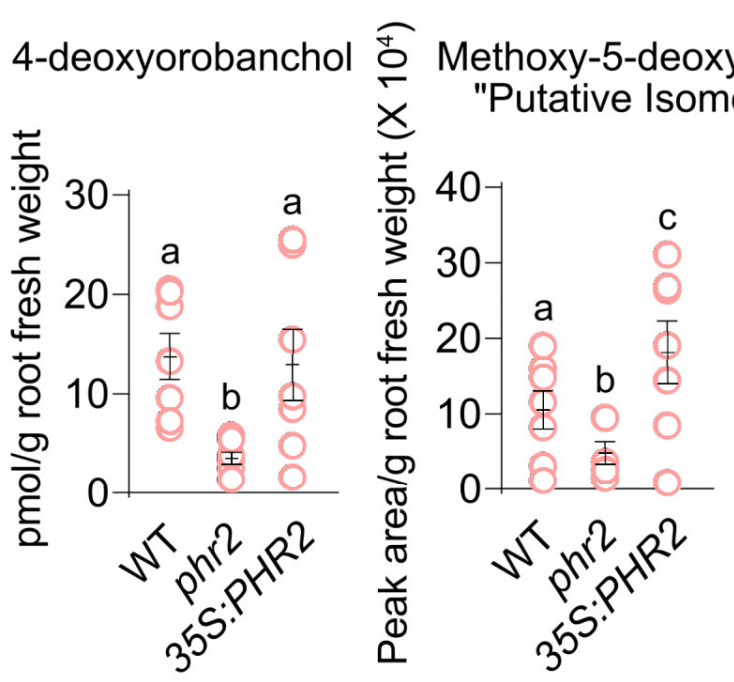

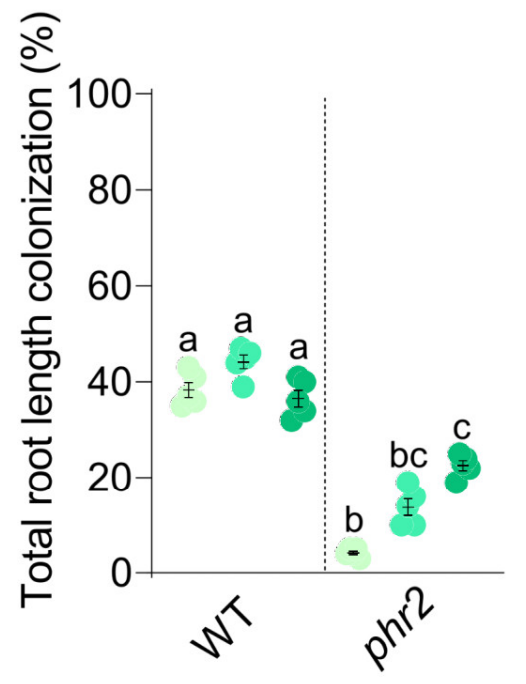

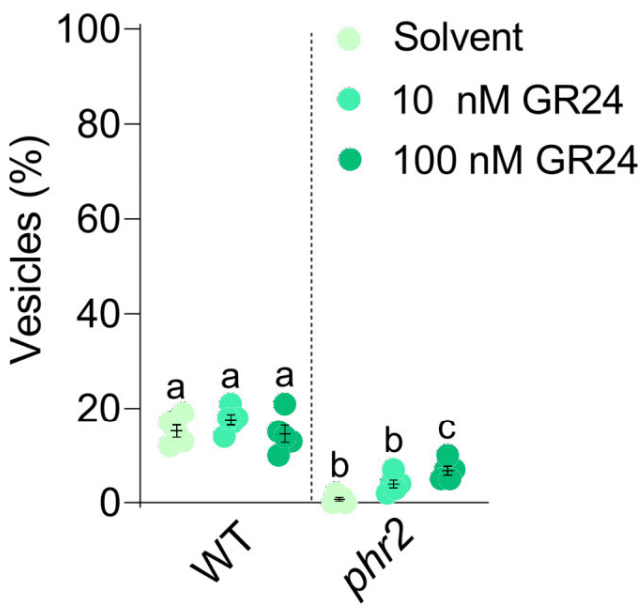


Figure 4

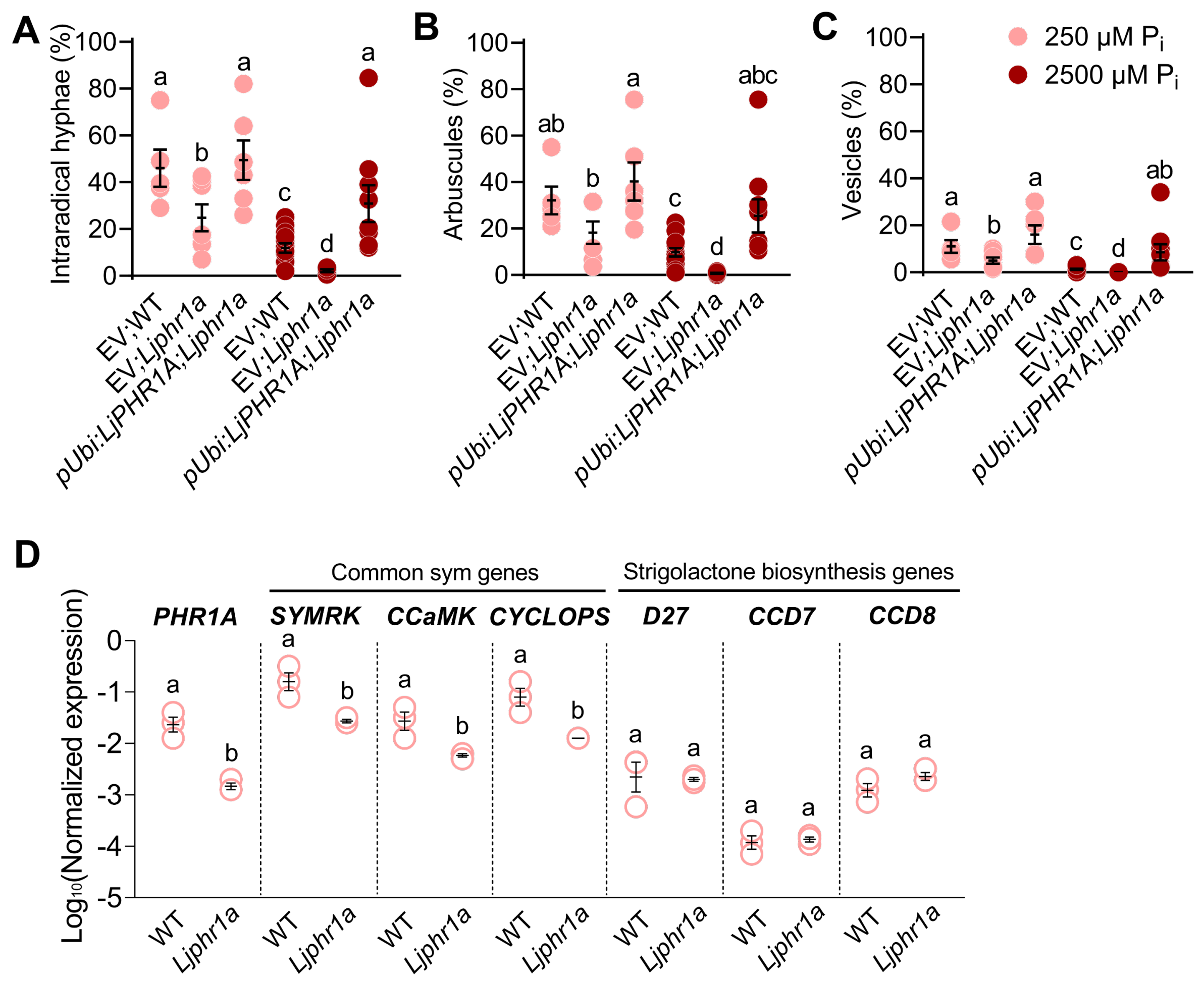


Figure 5

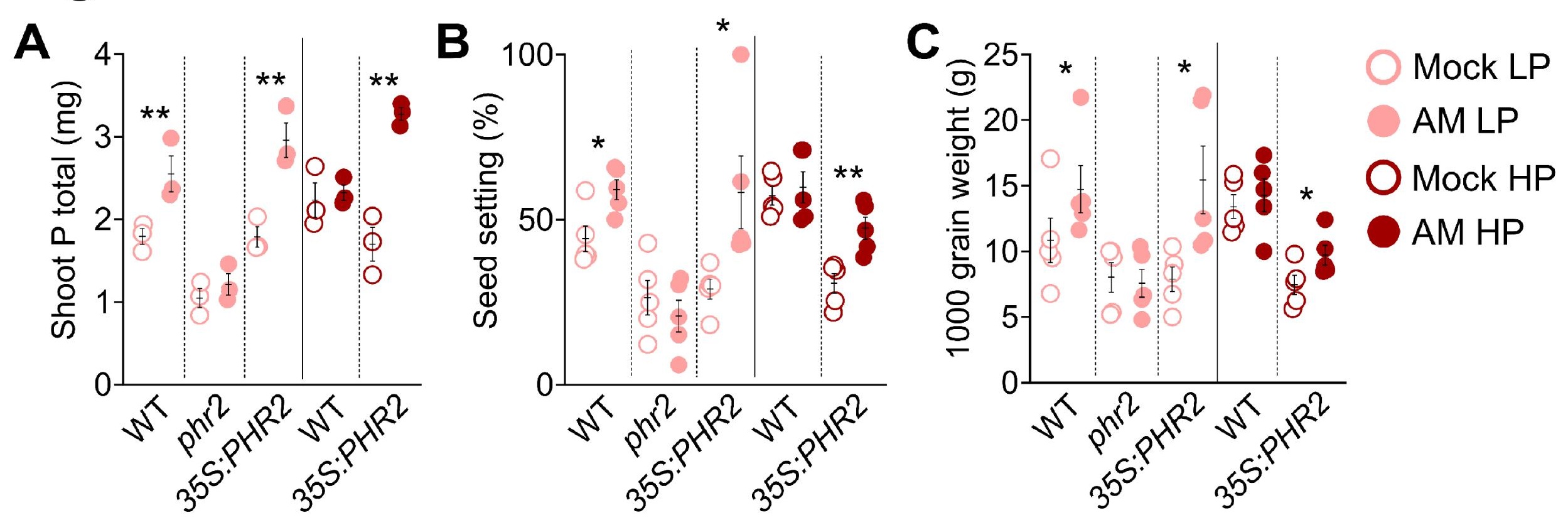


